\title{
Nanobiosensor Reports on CDK1 Kinase Activity in Tumor Xenografts in Mice
}

Carmen Mihaela Tîlmaciu ${ }^{1} \dagger$, Bhimareddy Dinesh ${ }^{2} \dagger$, Morgan Pellerano ${ }^{1}$, Sebastien Diot ${ }^{1}$, Mélanie Guidetti ${ }^{3}$, Julien Vollaire ${ }^{3}$, Alberto Bianco ${ }^{2}$, Cécilia Ménard-Moyon ${ }^{2 *}$, Véronique Josserand $^{3 *}$, May C. Morris ${ }^{1 *}$

C.M. Tilmaciu. Author 1, Dr. M. Pellerano. Author 3, S. Diot. Author 4, Dr. M.C. Morris, Last Author

${ }^{1}$ Institut des Biomolécules Max Mousseron-CNRS, UMR5247, Université de Montpellier, 34093 Montpellier, France

E-mail: may.morris@umontpellier.fr

Dr. B. Dinesh Author 2, Dr. A. Bianco Author 7, Dr. C. Ménard-Moyon Author 8 ${ }^{2}$ CNRS, Immunology, Immunopathology and Therapeutic Chemistry, UPR 3572, University of Strasbourg, ISIS, 67000 Strasbourg, France

E-mail: c.menard@ibmc-cnrs.unistra.fr

Dr. M. Guidetti, Author 5, Dr. J. Vollaire, Author 6, Dr. V. Josserand, Author 9

${ }^{3}$ Institut pour l'Avancée des Biosciences, INSERM U1209, CNRS UMR-5309, Université

Grenoble Alpes, Grenoble, France

E-mail: veronique.josserand@univ-grenoble-alpes.fr

$†$ These authors contributed equally

Keywords: carbon nanotube, peptide biosensor, CDK1 kinase, fluorescence, cancer 


\begin{abstract}
Probing the dynamics and quantifying the activities of intracellular protein kinases that coordinate cell growth and division and constitute biomarkers and pharmacological targets in hyperproliferative and pathological disorders remains a challenging task. Here we describe engineering and characterization of a nanobiosensor of the mitotic kinase CDK1, through multifunctionalization of carbon nanotubes with a CDK1-specific fluorescent peptide reporter. This original reporter of CDK1 activity combines the sensitivity of a fluorescent biosensor with the unique physico-chemical and biological properties of nanotubes for multifunctionalization and efficient intracellular penetration. The functional versatility of this nanobiosensor enables implementation to quantify CDK1 activity in a sensitive and dose-dependent fashion in complex biological environments in vitro, to monitor endogenous kinase in living cells and directly within tumor xenografts in mice by fluorescence imaging, thanks to a ratiometric quantification strategy accounting for response relative to concentration in space and in time.
\end{abstract}




\section{Introduction}

One of the challenges of modern biology and medicine is to visualize biomolecules in their natural environment, in real-time and in a non-invasive fashion, so as to gain insight into their physiological behaviour and highlight alterations in clinically-relevant pathological settings. Moreover, the development of personalized medicine and targeted therapies calls for sensitive and selective means of detecting specific biomarkers in healthy versus pathological cells, so as to propose novel strategies for early-stage diagnostics, for monitoring disease progression and response to administration of therapeutics. Today, there is an urgent need for innovative sensing technologies, which allow for sensitive, rapid and non-invasive detection of biomarkers in situ, including intracellular enzymatic activities whose deregulation is associated with disease. In particular, protein kinases constitute an important class of enzymes, hyperactivation of which contributes and sustains human cancers, thereby constituting established biomarkers and attractive pharmacological targets. ${ }^{[1,2]}$. Cyclin-dependent kinases are heterodimeric serine/threonine protein kinases that play a central role in coordination of cell growth and division and participate in a wide variety of essential biological processes including transcription, tissue differentiation during development, metabolism and neuronal function. ${ }^{[3,4]}$ Altered activity of several cyclin-dependent kinases has been well documented in a large number of cancers and their contribution to stimulate and sustain unrestricted cell proliferation. ${ }^{[5-7]}$ As such they constitute attractive pharmacological targets for anticancer therapeutics. ${ }^{[8,9]}$ In particular, CDK1 constitutes the only essential CDK, responsible for coordination of the G2/M transition and progression through mitosis. ${ }^{[10,11]}$ However, despite the oncological relevance, prognostic value and pharmacological attractivity of cyclin-dependent kinases, diagnostic approaches for detecting and quantifying alterations in their activities are poorly developed, and there is a general lack of resources to monitor these biomarkers directly in situ. Probing intracellular protein kinases in their natural environment and quantifying their relative activity remains very challenging both in terms of specificity and sensitivity. Moreover, 
development of non-invasive sensing technologies to assess the activity of these biomarkers remains largely limited by intracellular penetration. Until the design of fluorescent kinase activity reporters, detection of protein kinase activity was essentially limited to indirect antigenic approaches enabling detection of phosphorylated substrates of the kinase of interest, following cell or tissue fixation or extraction, such as Western blotting and immunohistochemistry. Fluorescent biosensor technologies constitute powerful and sensitive tools for direct measurement of kinase activities, thereby providing promising perspectives for early detection of target dysregulation in disease, for "smart and personalized" diagnostics. ${ }^{[12,13]}$ However, whilst genetically-encoded FRET biosensors require transfection into living cells to image the dynamic behaviour of protein kinases, peptide- or protein-based biosensors engineered through incorporation of environmentally-sensitive synthetic probes are more suited to quantify sensitive differences in kinase activity but remain more challenging to be introduced efficiently in living cells and organisms. ${ }^{[14,15]}$

We previously developed a fluorescent biosensor technology enabling quantification of relative CDK/Cyclin activity (CDKACT) in cell extracts. CDKACT biosensors are synthetic modular peptides comprising a phosphoamino acid binding domain (PAABD) and a substrate derived moiety onto which an environmentally-sensitive dye is conjugated. Following phosphorylation by the CDK/Cyclin kinase, fluorescence emission of the biosensor is enhanced, due to local changes in fluorophore environment, prompted by interactions between the PAABD and the phosphorylated substrate. We have shown that these tools constitute sensitive and selective tools to report on $\mathrm{CDK} / \mathrm{Cyclin}$ activities in vitro, but require complementary technologies to mediate their efficient intracellular delivery for application in living cells. ${ }^{[16-18]}$. In this respect, carbon nanotubes (CNTs) provide several attractive opportunities to enable application of fluorescent biosensors to image kinase activity in living cells and animal models. Due to their outstanding optical, mechanical, electrical and thermal properties, CNTs constitute alluring materials for biological applications ${ }^{[19-21]}$ such as drug delivery, ${ }^{[22]}$ photothermal therapy, ${ }^{[23]}$ 
biosensing, ${ }^{[24,25]}$ and tissue engineering. ${ }^{[26]}$ In particular, thanks to their high specific surface area, they constitute functionalizable platforms, scaffolds of choice for immobilization or covalent conjugation of a wide variety of bioactive molecules including peptides, antibodies, and protein receptors. ${ }^{[27-30]}$ CNTs have shown a remarkable capacity to be internalized in cells through crossing the cell membranes within minutes by direct translocation into the cytoplasm or via an energy-dependent mechanism, such as endocytosis. ${ }^{[31]}$ In addition, precise control of their surface chemistry enables engineering of multimodal nanotubes and reduction of their pathogenicity. ${ }^{[32-34]}$

In this study, we report on the development of CNT-peptide biosensor conjugates designed to report and quantify relative activity of CDK1 kinase in vitro, in living cells and in vivo. We describe conjugation of a fluorescent CDK1-specific peptide biosensor at the outer surface of multi-walled CNTs (MWCNTs), in vitro characterization and their implementation to quantify CDK1 activity in living cells and in mice bearing melanoma tumor xenografts by fluorescence imaging.

\section{Results}

\subsection{Engineering a CNT-peptide biosensor that reports on CDK1/Cyclin B1 activity}

We previously developed a toolbox of bipartite polypeptide biosensors comprising a CDK substrate sequence associated with a PAABD derived from Polo kinase, and a shorter version derived from the WW of the prolyl isomerase Pin1. ${ }^{[16-18]}$ These fluorescent protein and peptide biosensors report on CDK/Cyclin activities through sensitive changes in fluorescence intensity of environmentally-sensitive dyes conjugated to the substrate moiety of the biosensor in response to kinase activities that phosphorylate the substrate. In order to develop a CDK1specific peptide biosensor, we designed and synthesized a peptide reporter comprising a substrate sequence derived from the autophosphorylation site of Cyclin B1 by CDK $1^{[35]}$ and a PAABD derived from the WW domain of Pin1 (Figure 1A) and further designed a strategy to 
engineer a CDK1 nanobiosensor through multifunctionalization of MWCNTs (Figure 1B). Specifically, a first generation of CNT-peptide biosensor conjugates was prepared between MWCNTs functionalized by amidation with a $\mathrm{COOH}$-terminated triethylene glycol (TEG) hydrophilic linker and the N-terminal lysine side chain amine of CDKACT1-Rhodamine peptide (CDKACT1-Rhoda) (Figure 1C and S1A). First, carboxylic acid groups were introduced on the nanotubes, mainly at the tips, by oxidizing MWCNTs using a (3:1) mixture of sulphuric acid and nitric acid under sonication, which yielded short nanotubes with an average length of $\sim 270 \mathrm{~nm}$ that were highly dispersible in water (Supplementary Figure S1B). The oxidized MWCNTs (ox-MWCNTs) were derivatized with a Boc-monoprotected TEG diamine by amidation via activation of the carboxylic acids using oxalyl chloride followed by Boc deprotection using $\mathrm{HCl}$ to yield $f$-MWCNTs 4. Successive derivatization of the amino groups with succinic anhydride yielded $f$-MWCNTs 5. Amine loading determined by the colorimetric Kaiser test was 203 and $58 \mu \mathrm{mol} / \mathrm{g}$ for $f$-MWCNTs 4 and 5, respectively. The lower amine loading confirmed the successful functionalization of the amino functions with succinic anhydride. Next, the $\mathrm{COOH}$ groups of $f$-MWCNTs 5 were activated using $N$ hydroxysuccinimide (NHS) allowing the reaction with the lysine side chain at the N-terminus of the CDKACT1-Rhoda biosensor peptide giving $f$-MWCNTs 6a. The CNT-peptide biosensor conjugate was characterized by thermogravimetric analysis (TGA) and transmission electron microscopy (TEM). TGA was performed under an inert atmosphere to evaluate the degree of functionalization (Supplementary Figure S1C). The pristine CNTs were stable up to $800^{\circ} \mathrm{C}$, while $o x$-MWCNTs 1 showed an increased weight loss due to the release of the carboxylic groups from the nanotube surface. The weight loss further increased after derivatization by amidation and peptide conjugation. The amount of peptide on the CNTs corresponded to the weight loss difference between $f$-MWCNTs $\mathbf{6 a}$ and $\mathbf{5}$ at $500^{\circ} \mathrm{C}(9.8 \mu \mathrm{mol}$ of peptide per gram of CNT conjugate). TEM analysis showed that the morphology of the nanotubes was not affected by the different chemical treatments (Supplementary Figure S1B). 


\subsection{Monitoring response of CNT-CDKACT1-Rhoda conjugates to kinase activity in vitro}

CNT-CDKACT1-Rhoda conjugates were first characterized in vitro to assess their response to recombinant CDKs and HeLa cell extracts as a source of CDK kinase activity.

In order to validate the specific response of CNT-CDKACT1-Rhoda to CDK1 activity, we first compared its response to recombinant CDK1/Cyclin B1 and to the closely related CDK2/Cyclin A (Figure 2A and B). The optimal conditions for biosensor response were determined in two sets of dose-dependent experiments using a fixed concentration of CDK1/Cyclin B1 (75 nM) and varying concentrations of CNT-CDKACT1-Rhoda biosensor from 0 to $500 \mathrm{nM}$ (corresponding to $0-51 \mu \mathrm{g} / \mathrm{mL}$ of CNTs), and conversely a fixed concentration of CNTCDKACT1-Rhoda biosensor (250 nM fluorescent peptide) and different concentrations of recombinant CDK1/Cyclin B1 (Supplementary Figure S2). These experiments revealed that the CNT-CDKACT1-Rhoda conjugates responded to CDK1 activity in a more sensitive and robust fashion than CDKACT1-Rhoda peptide biosensor alone at the same molar concentration (determined by quantifying peptide fluorescence), with optimal response observed for $250 \mathrm{nM}$ CNT-CDKACT1-Rhoda. Neither CNT-CDKACT1-Rhoda conjugates nor CDKACT1-Rhoda peptide biosensor alone responded to CDK2 activity in similar dose-dependent doses, irrespective of biosensor or kinase concentration, indicative of specific peptide biosensor response to $\mathrm{CDK} 1$ over $\mathrm{CDK} 2$, as expected from its initial design derived from the autophosphorylation sequence of Cyclin B1 (Supplementary Figure S3). As a negative control, the CDKACT1 peptide labelled with Dylight650 (Dy650) revealed the importance of an environmentally-sensitive probe such as rhodamine for biosensor response to kinase activity, as previously reported for CDKACT4 and CDKACT5 biosensors. ${ }^{[17,18]}$

We further evaluated the ability of CNT-CDKACT1-Rhoda to report on CDK1 activity in HeLa cell extracts as a source of kinase activity. Again, dose-dependent characterization of CNTCDKACT1-Rhoda was performed with a fixed concentration of HeLa cell extract $(40 \mu \mathrm{g})$ incubated with different concentrations of CNT-CDKACT1-Rhoda biosensor from 0 to $750 \mathrm{nM}$ 
and conversely a fixed concentration of CNT-CDKACT1-Rhoda biosensor and different concentrations of HeLa cell extracts from 0 to $80 \mu \mathrm{g}$ (Figure 2C and Supplementary Figure S4A). As observed with recombinant CDK1/Cyclin B1, response of CNT-CDKACT1-Rhoda conjugate to CDK1 activity in HeLa cell extracts was far more significant than that of CDKACT1-Rhoda peptide biosensor at the same molar concentration (determined by quantifying peptide fluorescence) and CDKACT1-Dy650 served as a negative control to validate the importance of rhodamine in the optical transduction of kinase activity (Supplementary Figure S4A).

Last but not least, we verified whether the response of CNT-CDKACT1-Rhoda conjugates to recombinant $\mathrm{CDK} 1 / \mathrm{Cyclin} \mathrm{B} 1$ or to $\mathrm{CDK} 1$ in HeLa cell extracts was abolished by the pan-CDK inhibitor Roscovitine, thereby confirming that CDKACT1-Rhoda peptide biosensor and CNTCDKACT1-Rhoda conjugates indeed responded to CDK1 activity, rather than simply detecting its presence (Figure 2A and C, Supplementary Figure S4B).

Taken together, these experiments revealed the superior response of CNT-CDKACT1-Rhoda conjugates over CDKACT1-Rhoda peptide biosensor alone.

\subsection{Cellular uptake and fluorescence imaging of CNT-CDKACT1-Rhoda response to}

\section{CDK1 activity in HeLa cells}

Following in vitro characterization, CNT-CDKACT1-Rhoda conjugate was introduced into cultured HeLa cells for further evaluation in a cellular environment. First, the optimal conditions of CNT-CDKACT1-Rhoda internalization for imaging in HeLa cells were determined by overlaying different concentrations of conjugates dispersed in water/glucose by sonication and varying the kinetics of cellular uptake (CNT-biosensor overlay on cells) as well as the recovery (time following overlay). Cellular penetration efficiency of the CNT-biosensor conjugate in living cells was evaluated by fluorescence microscopy. Homogeneous internalization and biosensor fluorescence was observed using submicromolar concentrations 
(typically $0.5 \mu \mathrm{M}$ ) of CNT-CDKACT1-Rhoda overlaid on cells for $20 \mathrm{~min}$, and observed after 45 min recovery (Figure 3A and Supplementary Figure S5A). In comparison, CDKACT1 peptide alone, unconjugated to CNTs, was essentially unable to enter cells.

To further validate the ability of CNT-CDKACT1-Rhoda to report on CDK1 activity following internalization into HeLa cells we quantified its fluorescence emission prior to and following $24 \mathrm{~h}$ treatment with the CDK inhibitor Roscovitine (Figure 3B). Specifically, ratiometric quantification of rhodamine fluorescence relative to fluorescence of Hoechst nuclear staining in HeLa cells which had been treated with Roscovitine was significantly reduced and almost completely abolished compared to relative rhodamine/Hoechst fluorescence in untreated HeLa cells (Figure 3D). For comparison the relative fluorescence of CDKACT1-Rhoda/Hoechst following overlay on HeLa cells in the same conditions as for the CNT-biosensor conjugate was not only significantly reduced, as the peptide alone did not penetrate cells, there was essentially no difference between untreated and Roscovitine-treated cells (Figure 3C and D). These experiments revealed that the CNT-CDKACT1-Rhoda biosensor can be used to monitor alterations in CDK1 activity in living cells by fluorescence microscopy.

We further asked whether the CNT-CDKACT1-Rhoda nanobiosensor might induce any toxicity following internalization into cultured cells. To this aim, cell viability studies were performed in HeLa cells by crystal violet staining, so as to compare untreated cells and mocktreated cells, which were treated with $5 \%$ glucose/PBS, CNT-CDKACT1-Rhoda or the precursor $f$-MWCNTs 5 devoid of peptide. The concentration of CNT conjugates was 50 $\mu \mathrm{g} / \mathrm{mL}$, corresponding to $0.5 \mu \mathrm{M}$ of peptide, because it is to the concentration used for the observation of the fluorescence signal and the determination of the kinase activity in cultured cells. The cell viability studies revealed that cells treated with MWCNTs whether conjugated or not to CDKACT1 retained $80 \%$ viability after $24 \mathrm{~h}$ and about $70 \%$ after $48 \mathrm{~h}$, relative to untreated cells (Supplementary Figure S5B). 


\subsection{Biodistribution and fluorescence imaging studies of CNT-CDKACT1 in mice}

Due to the absorption and diffusion properties of light into tissues, non-invasive detection of fluorescence in mice requires using near-infrared (NIR) wavelengths $(650-900 \mathrm{~nm}) .{ }^{[36]}$

To this aim, a CDKACT1-Cy5 peptide biosensor derivative and a CNT-CDKACT1-Cy5 conjugate were prepared as well as a control CNT conjugate functionalized with a control peptide (CNT-NanoCtrl-Cy5), derived from a previously described kinase-unrelated sequence that does not bind CDKs. ${ }^{[37]}$ The CNT-NanoCtrl-Cy5 peptide conjugate $6 \mathbf{b}$ was prepared following the strategy used for the synthesis of the CNT-CDKACT1-Rhoda 6a (Figure 1B and Supplementary Figure 1A). Peptide loading assessed by TGA was $17.6 \mu \mathrm{mol}$ per g of CNT conjugate (Supplementary Figure 1C).

CNT-NanoCtrl-Cy5 (200 $\mu \mathrm{L}$ at $6 \mu \mathrm{M}$ as quantified by Cy5 fluorescence) was injected intravenously into mice to evaluate its biodistribution and pharmacokinetics (Supplementary Figure S6A). Mice showed no signs of suffering or discomfort until they were killed $24 \mathrm{~h}$ after injection.

The fluorescence emission of CNT-NanoCtrl-Cy5 was linear up to $10 \mu \mathrm{M}$ without quenching and could be detected down to $275 \mathrm{nM}$ which was a sufficient sensitivity to enable non-invasive in vivo imaging in the mouse. This conjugate was eliminated at an early stage (starting 30 min after injection and during the first $5 \mathrm{~h}$ ), mainly through the bladder and to a lesser extent through the hepatobiliary pathway. Twenty-four after injection, CNTs had been totally eliminated from the mouse body, resulting in a lack of residual signal in the ex vivo tissue analyses during which isolated organs were carefully examined and no abnormalities were observed (Supplementary Figure S6A). These results are consistent with previous studies using MWCNTs functionalized with different contrast agents. ${ }^{[38,39]}$

The ability of the nanobiosensor to reach the tumor after systemic injection was then evaluated in tumor-bearing mice. Mice were implanted subcutaneously with human melanoma cells (A375) and tumor growth was monitored by caliper measurements until the tumor volume 
reached $250 \pm 26 \mathrm{~mm}^{3}$ (Supplementary Figure S6B). As observed for CNT-NanoCtrl-Cy5 in healthy mice, no signs of suffering or discomfort were detected and the CNT-CDKACT1-Cy5 conjugate was eliminated through renal and urinary pathways and to a lesser extent through the hepatobiliary pathway, resulting in a very weak tumor contrast when using this administration route (Supplementary Figure S6B). Ex vivo tissue analyses $5 \mathrm{~h}$ after the injection evidenced no abnormalities and corroborated the in vivo observations by showing residual fluorescence mainly in the kidney, intestine, liver and only very modestly in the tumor, skin and spleen (Supplementary Figure S6B).

To further concentrate the signal in the tumor, the CNT-NanoCtrl-Cy5 conjugate was injected directly into the tumor ( $100 \mu \mathrm{L}$ at $1 \mu \mathrm{M}$ as determined by quantification of Cy5 fluorescence) and non-invasive fluorescence imaging was used to monitor tumor retention of this control conjugate (Figure 4). The CNT-NanoCtrl-Cy5 conjugate was slowly washed out from the tumor as evidenced by $82 \pm 7 \%$ fluorescence in the tumor 1 hour after injection and more than $50 \%$ fluorescence still present in the tumor $2 \mathrm{~h}$ after injection.

In order to develop a strategy for quantitative monitoring of CDK1 activity in vivo, the relative concentration of biosensor present in the tumor at a given time had to be integrated into the quantification procedure. To this end, we first established conditions for co-injection and simultaneous detection of two conjugates in vivo in mice, the one reporting on CDK1 activity (CNT-CDKACT1-Cy5), the other simply reporting on the presence of CNT conjugates and serving as a control for normalizing the fluorescence signal of the biosensor relative to its in vivo distribution and in particular its concentration in the tumor, and this, regardless of the tumor volume. To this aim, and since fluorescence spectra of both fluorophores had to be sufficiently separated to be well discriminated for fluorescence signal quantification, a control CNT conjugate functionalized with the control peptide labelled with Dylight755 (CNTNanoCtrl-Dy755) was prepared. 
The CNT-CDKACT1-Cy5 nanobiosensor and CNT-NanoCtrl-Dy755 control were prepared by implementing a double functionalization strategy involving combination of amidation and 1,3dipolar cycloaddition (Figure 1C and Supplementary Figure S7A), so as to enable a second step of CNT functionalization at a later stage with both CDKACT1-Cy5 biosensor peptide and a separate fluorophore to yield a unique double-fluorescent conjugate for self-ratiometric quantification. The $o x$-MWCNTs 1 were functionalized first by 1,3-dipolar cycloaddition of in situ generated azomethine ylides and then by amidation between the carboxylic acids at the tips and a phthalimide-monoprotected TEG diamine linker. The Pht group on $f$-MWCNTs $\mathbf{1 0}$ was deprotected by treating with hydrazine and the amine loading assessed by the Kaiser test was $87 \mu \mathrm{mol} / \mathrm{g}$. Successive reaction with succinic anhydride led to a reduced Kaiser test value (20 $\mu \mathrm{mol} / \mathrm{g}$ ) confirming the successful amine derivatization. The CNT-CDKACT1-Cy5 13a and CNT-NanoCtrl-Dy755 13b were prepared by conjugating the corresponding dye-labelled peptides to $f$-MWCNTs 12 after NHS activation. The level of functionalization was 28.9 and $16.9 \mu \mathrm{mol} / \mathrm{g}$ for $f$-MWCNT 13a and 13b, respectively, based on TGA (Supplementary Figure S137B).

Like the rhodamine-labelled biosensor peptide, the Cy5-labelled CNT-CDKACT1 derivative responded to CDK1 kinase activity in vitro using HeLa cell extracts as a source of kinase (Supplementary Figure S8A) and both CNT-CDKACT1-Cy5 and CNT-NanoCtrl-Dy755 were efficiently internalized in living HeLa cells (Supplementary Figure S8B).

Subsequently, seven mice with subcutaneous A375 melanoma tumors received an intratumoral co-injection of CNT-CDKACT1-Cy5 and CNT-NanoCtrl-Dy755 conjugates (25 $\mu \mathrm{L}$ at $10 \mu \mathrm{M}$ each as quantified by the absorbance of their fluorescent probe) and dual fluorescence imaging at suitable wavelengths was performed immediately after injection $\left(T_{i}\right)$, then $1 \mathrm{~h}$ and $2 \mathrm{~h}$ postinjection (Figure 5A). At each imaging time point CNT-nanobiosensor/CNT-control conjugate fluorescence ratio was calculated (CNT-CDKACT1-Cy5/CNT-NanoCtr1-Dy755) and expressed as a percentage of the $\mathrm{T}_{\mathrm{i}}$ ratio obtained immediately after the injection. Thus, any 
increase in this ratio reports on nanobiosensor response to $\mathrm{CDK} 1$ kinase activity relative to the concentration of CNT conjugates, i.e. independently of its biodistribution. The two conjugates showed clearly distinct fluorescence signal kinetics, CNT-NanoCtrl-Dy755 showing a fluorescence decay in relation to its elimination from the tumor (as previously observed for CNT-NanoCtrl-Cy5) and CNT-CDKACT1-Cy5 exhibiting an increase in fluorescence related to biosensor response to CDK1 activity. Ratiometric quantification/analysis of these two fluorescence kinetics results in a Cy5/Dy755 ratio increase by a factor of 3.5 during the first hour post-injection thereby clearly validating nanobiosensor response to CDK1 activity within the tumor tissue (Figure 5B).

To enable ratiometric quantification of nanobiosensor response to CDK1 activity relative to its concentration in space and time using one single conjugate comprising two distinct fluorescent species (biosensor and probe for signal normalization), we finally prepared doublefluorescently-labelled CNT conjugates by functionalizing CNTs with both CDKACT1-Cy5 peptide and Alexa Fluor $^{\circledR} 750$ (Alexa750) as control probe. We unfortunately first experienced fluorescence quenching when Alexa750 dye was coupled directly to CNTs through the TEG linker probably due to energy/charge transfer between the dyes because of their close proximity. Hence, we designed an alternative strategy to conjugate the fluorophore by using click chemistry. To this aim, a modified $\mathrm{PEG}_{10}$ linker bearing an alkyne moiety at one end and Alexa750 at the other end was synthesized (Supplementary Figure S9A). After Boc cleavage of the double functionalized MWCNTs 12 in acidic conditions, the amino groups were derivatized by amidation with 5-azidopentanoic acid (Figure 1D and Supplementary Figure S9B). The copper-catalyzed azide-alkyne cycloaddition (CuAAC) reaction was performed between azido-MWCNTs 18 and the alkyne-PEG-Alexa750 linker 16 using a catalytic amount of copper(II) sulphate and sodium ascorbate to yield Alexa750-labelled $f$-MWCNTs 19. The activation of the $\mathrm{COOH}$ groups with NHS followed by amidation with CDKACT1-Cy5 peptide 
yielded nanobiosensor 20 with a level of functionalization of $18.0 \mu \mathrm{mol} / \mathrm{g}$ according to TGA (Supplementary Figure S9C).

The double-labelled nanobiosensor 20 was injected into melanoma tumors and dual fluorescence imaging at suitable wavelengths was performed immediately after injection (Ti), then $30 \mathrm{~min}, 1 \mathrm{~h}$ and $2 \mathrm{~h}$ post-injection (Figure 6A). Mice injected with the nanobiosensor showed an increase in Cy5 fluorescence emission associated with only a very weak variation in the Alexa750 signal (Figure 6B), resulting in a net increase in the Cy5/Alexa750 fluorescence ratio indicative of biosensor response to CDK1 activity within tumor xenografts (Figure 6C). To confirm whether the nanobiosensor could further report on physiological variations of CDK1 activity directly in vivo, eight mice were treated twice by intraperitoneal co-injection of the pan-CDK inhibitor Roscovitine $(50 \mathrm{mg} / \mathrm{kg})$ and the CDK1-inhibitor RO-3306 (4 mg/kg) first for one day and then again for $1 \mathrm{~h}$, before injection of nanobiosensor $\mathbf{2 0}$, while eight other mice received the vehicle only. Roscovitine is a pan-CDK inhibitor, which primarily inhibits CDK2 and leads to accumulation of cells in S-phase, whereas the CDK1 inhibitor RO-3306 blocks cells at the G2/M transition. ${ }^{[40]}$ The double treatment with Roscovitine and RO-3306 was initially intended to completely block CDK activity in the tumor, since previous studies had revealed intraperitoneal administration of Roscovitine alone in this melanoma tumor model was insufficient to block CDK activity completely. However, mice treated with Roscovitine and RO-3306 exhibited a significantly higher increase in the nanobiosensor Cy5 fluorescence emission compared to vehicle-treated mice $(\times 2.5$ for the treated group $v s \times 1.6$ for the vehicle group at 30 min post-injection; **p-value $<0.01$ ), associated with a very slight variation in Alexa750 fluorescence (Figure 6B), resulting in an overall greater increase in Cy5/Alexa750 fluorescence ratio for the treated group compared to the vehicle group (Figure 6C). The nanobiosensor was therefore indeed capable of reporting on greater CDK1 activity in mice treated with Roscovitine and RO3306 in these experimental conditions. This difference was most significant $2 \mathrm{~h}$ post-injection (*p-value $<0.05)$, inferring that a minimal lapse of time was 
probably required for the nanobiosensor to penetrate the tumor cells and respond effectively to active CDK1 kinase. To understand why the double Roscovitine/RO3306 treatment led to an unexpected increase in CDK1 activity, we asked whether it might be due to synchronized release of cells from a Roscovitine-induced S-phase block, resulting in simultaneous activation of CDK1/Cyclin B1, RO3306 being insufficient to inhibit CDK1 activity when coadministrated with Roscovitine, which preferentially leads to an S-phase block. To this aim we treated cultured A375 cells with Roscovitine and RO3306 using the same conditions as for tumor treatment in mice and examined the levels of cyclin B1 and phospho-cyclin B1, the latter being indicative of CDK1 activity and cyclin B1 autophosphorylation. Indeed, consistent with the nanobiosensor response observed in vivo, Western blot analysis of A375 cells treated for 24 h with Roscovitine or with Roscovitine and RO3306, revealed the presence of phosphorylated Cyclin B1, associated with CDK1 activity, in contrast to a $48 \mathrm{~h}$ Roscovitine treatment, which completely abolished Cyclin B1 autophosphorylation. Moreover, release from a $24 \mathrm{~h}$ Roscovitine or Roscovitine + RO3306 block (mimicking a likely release of tumor cells following the first treatment in vivo) followed by a second $1 \mathrm{~h}$ Roscovitine or Roscovitine/RO3306 treatment, (as performed in vivo) was insufficient to inhibit CDK1 and led to further accumulation of phosphorylated Cyclin B (Supplementary Figure S10). These in vitro studies hence confirmed that the nanobiosensor indeed reports on CDK1 activation following release from a Roscovitine or Roscovitine/RO3306 block, in agreement with in vivo experiments.

\section{Conclusion}

Together with the development of molecular imaging technologies, fluorescent biosensors constitute powerful and sensitive tools to monitor the activity of intracellular targets. Bioprobes or biosensors that can detect and report on molecular anomalies in malignant cells are of major interest for development of diagnostics and associated therapeutic strategies. In this respect, 
environmentally-sensitive peptide biosensors constitute attractive tools, but their application to monitor dynamic and enzymatic processes in living cells is hampered by their inability to cross cell membranes, calling for strategies to enable their intracellular delivery.

CNTs constitute efficient carriers, given their remarkable cell-penetrating capacity and constitute attractive platforms for multifunctionalization, due to their high specific surface area. In this study, we have exploited these exceptional properties to engineer an original nanobiosensor of CDK1 activity through conjugation of multiple copies of an environmentallysensitive fluorescent peptide biosensor derived from the autophosphorylation site of Cyclin B1 at the surface of carbon nanotubes.

Not only is CNT-CDKACT1 the first CNT reporter of kinase activity, we have shown it could be implemented for fluorescence-based detection and quantification of CDK1 activity in vitro, in living cells and in vivo. Indeed, this nanobiosensor responds to active recombinant CDK1/Cyclin B1 and to endogenous kinase activity in HeLa cell extracts in a sensitive and dose-dependent fashion, penetrates efficiently into living cells and can report on kinase activity by fluorescence imaging. Furthermore, its optimization to generate a double-labelled nanobiosensor enabled us to monitor CDK1 activity in vivo within tumor xenografts, thanks to a ratiometric quantification strategy accounting for the relative concentration of the nanobiosensor in space and in time.

The originality of this nanobiosensor is that beyond simple detection of CDK1, it can report on its enzymatic activity, thereby providing information concerning kinase function in a complex environment. Since alterations in $\mathrm{CDK} /$ cyclin activity have been reported in a wide variety of cancers and associated with negative prognosis, we anticipate that our technology should provide a direct means of probing hyperactivation of these kinases, and of guiding therapeutic intervention/decision, thereby contributing to cancer diagnostics, assisting therapeutic programs, and monitoring response to therapeutics. 


\section{Experimental Section/Methods}

\subsection{Preparation of the CNT conjugates}

\subsubsection{Chemicals, characterization methods and instrumentation}

Pristine multi-walled carbon nanotubes (MWCNTs) (20-30 nm diameter, 0.5-2 $\mu \mathrm{m}$ length, 95\% purity; batch 1240XH) were purchased from Nanostructured and Amorphous Materials. The linker $O$-(2-aminoethyl)-O'-[2-(Boc-amino) ethyl]decaethylene glycol was purchased from Polypure AS company and used as it was received. Alexa Fluor ${ }^{\circledR} 750$ free acid tris(triethylammonium) salt was purchased from Fisher Scientific. The dry solvents and $4 \mathrm{M}$ $\mathrm{HCl}$ in 1,4-dioxane were purchased from Sigma-Aldrich and were used as supplied. All other reagents were obtained from commercial suppliers and used without further purification. The CNT suspensions were sonicated in a water bath using either a Transsonics Digitals Elma sonicator $(20 \mathrm{~W}, 40 \mathrm{kHz})$ or an Elmasonic P30H (37 kHz) sonicator. The Spectra/Por ${ }^{\circledR}$ dialysis membrane (standard RC tubing MWCO: 12-14 kDa) was purchased from SpectrumLabs.

\subsubsection{Functionalization of MWCNTs}

The protocols for the synthesis of the precursor CNTs and the alkyne-PEG-Alexa750 linker 16 are descried in the Supplementary Materials.

Preparation of functionalized MWCNTs $\boldsymbol{6} \boldsymbol{a}$ and $\boldsymbol{6} \boldsymbol{b}$

\section{a) NHS activation}

To a suspension of $f$-MWCNTs $5(10 \mathrm{mg})$ in anhydrous DMF $(6 \mathrm{~mL})$ sonicated in a water bath for $10 \mathrm{~min}$, were added $N$-(3-dimethylaminopropyl)- $N$ '-ethylcarbodiimide hydrochloride (EDC.HCl) and $N$-hydroxysuccinimide (NHS) $(50 \mathrm{mg}$ ). The mixture was sonicated for $10 \mathrm{~min}$ and stirred under argon for $24 \mathrm{~h}$. The reaction mixture was filtered over a PTFE membrane $(0.1 \mu \mathrm{m})$. The solid recovered on the filter was dispersed in DMF $(75 \mathrm{~mL})$. The suspension was sonicated for $5 \mathrm{~min}$ in a water bath and filtered. This sequence was repeated successively with 
DMF, methanol, and dichloromethane. The solid was dried under vacuum to give NHS-derived MWCNTs.

\section{b) Peptide conjugation}

The dye-labelled peptide NanoCtrl-Cy5 $(2 \mathrm{mg})$ was solubilized in a mixture of MilliQ ${ }^{\circledR}$ water (1.9 mL) and $\mathrm{CH}_{3} \mathrm{CN}(0.1 \mathrm{~mL})$, and the solution was then added to the NHS-derived MWCNTs (6 mg) pre-dispersed in $2 \mathrm{~mL}$ of MilliQ water by sonication in a water bath for $5 \mathrm{~min}$. The reaction mixture was sonicated for $1 \mathrm{~min}$ and stirred for $16 \mathrm{~h}$ in the dark. The progress of the conjugation reaction was monitored by HPLC. Aliquots of $40 \mu \mathrm{L}$ of the reaction mixture diluted with $100 \mu \mathrm{L}$ of MilliQ water was centrifuged to analyse the supernatant solution by HPLC. The detected peak in HPLC corresponded to the unreacted peptide in the supernatant solution. After $16 \mathrm{~h}$, the reaction mixture was diluted by adding $20 \mathrm{~mL}$ of MilliQ water and filtered over a PTFE membrane $(0.1 \mu \mathrm{m})$. The solid recovered on the filter was dispersed again in MilliQ water and filtered. This washing sequence was repeated until the filtrate was colourless indicating that the free peptide was eliminated. Finally, the solid was dispersed in MilliQ water, the suspension was dialyzed against MilliQ water to remove any trace of free peptide and lyophilized to obtain conjugate CNT-NanoCtrl-Cy5 $6 \mathbf{b}$.

This protocol was followed for the preparation of CNT-CDKACT1-Rhoda conjugate $6 \mathbf{a}$ using the dye-labelled peptide CDKACT1-Rhoda and freshly prepared NHS-derived MWCNTs.

TEM images showed the intact morphology of the nanotubes after the different chemical treatments (Supplementary Figure S1B). According to TGA the peptide loading was found to be 9.8 and $17.6 \mu \mathrm{mol} / \mathrm{g}$ for $f$-MWCNTs $6 \mathbf{a}$ and $\mathbf{6 b}$, respectively (Supplementary Figure S1C).

\section{Preparation of functionalized MWCNTs $13 \boldsymbol{a}$ and $\mathbf{1 3 b}$}

\section{a) NHS activation}

The protocol used for NHS activation of $f$-MWCNTs 5 was applied starting from $f$-MWCNTs 12. 


\section{b) Peptide conjugation}

The protocol used to synthesize $f$-MWCNTs $\mathbf{6 a}$ and $\mathbf{6 b}$ was applied for the preparation of $f$-MWCNTs 13a and 13b using $5 \mathrm{mg}$ of the NHS-derived $f$-MWCNTs and $1.78 \mathrm{mg}$ of dyelabelled peptide CDKACT1-Cy5 and $1.03 \mathrm{mg}$ of dye-labelled peptide NanoCtrl-Dy755, respectively.

According to TGA the peptide loading was found to be 28.9 and $16.9 \mu \mathrm{mol} / \mathrm{g}$ for $f$-MWCNTs

13a and 13b, respectively (Supplementary Figure S7B). TEM analysis showed the preserved morphology of the nanotubes after the different chemical treatments (Supplementary Figure S1B).

Synthesis of functionalized MWCNTs 20

a) NHS activation

The protocol used for the NHS activation of $f$-MWCNTs 5 was applied starting from $f$-MWCNTs 19.

\section{b) Peptide conjugation}

A suspension of the NHS-derived MWCNTs $(6 \mathrm{mg})$ in MilliQ water $(2 \mathrm{~mL})$ previously sonicated in a water bath for $30 \mathrm{~s}$, was added to a solution of dye-labelled peptide CDKACT1-Cy5 $(3.4 \mathrm{mg})$ in a mixture of MilliQ water $(1.8 \mathrm{~mL})$ and acetonitrile $(0.2 \mathrm{~mL})$. The reaction mixture was sonicated for $30 \mathrm{~s}$ and stirred in the dark at room temperature. The monitoring of the reaction by HPLC and the work-up were done as mentioned in the protocol for the preparation of $f$-MWCNTs $\mathbf{6 b}$, giving $f$-MWCNTs 20. The peptide loading assessed by TGA was $18 \mu \mathrm{mol} / \mathrm{g}$ (Supplementary Figure S9C). TEM indicated that the different chemical treatments did not affect the morphology of the nanotubes (Supplementary Figure S1B). 


\subsection{Peptide biosensor design and preparation, biochemical and cellular characterization}

\subsubsection{Peptide synthesis and labelling}

CDKACT1 and NanoCtrl peptides were synthesized by GLS Biochem and purified to 95\%. They were labelled with a 10-fold molar excess of rhodamine- or Cy5-maleimide, then further purified on NAP5 columns (GE Healthcare) in $50 \mathrm{mM}$ TrisHCl, $\mathrm{pH} 7.4,150 \mathrm{mM} \mathrm{NaCl}$, to remove excess label as described previously in references ${ }^{16,17}$.

The sequence of CDKACT1 is: N-acetyl-KGWEGRMSRSSGRVYYFNHITNASQWERPSG GGPEPILVDCSSPSPMET. The sequence of NanoCtrl peptide is N-acetylKVESSDTIDNVKSKIQDKEGC.

\subsubsection{Dispersion of CNT-peptide biosensor conjugates for biological experiments}

CNT-peptide biosensors were dispersed in $5 \%$ glucose $/ \mathrm{H}_{2} \mathrm{O}$ at $100 \mu \mathrm{g} / 100 \mu \mathrm{L}$ stock concentrations and then diluted to the appropriate concentration required by serial dilution and sonication in a water bath for 5 min after each dilution.

\subsubsection{SDS-PAGE and Western blotting}

SDS-PAGE was performed according to standard protocols. Proteins were transferred onto PVDF membranes (Immobilon-P, Merck Millipore) for $2 \mathrm{~h}$ at $100 \mathrm{~V}$ in precooled Towbin buffer using a liquid BioRad system. Western blotting was performed according to standard procedures: membranes were first saturated with 5\% BSA in $50 \mathrm{mM}$ Tris, $\mathrm{pH} 7.2,150 \mathrm{mM}$ $\mathrm{NaCl}, 0.1 \%$ Tween, then incubated overnight at $4^{\circ} \mathrm{C}$ with the anti-cyclin $\mathrm{B} 1$ (Cell Signalling \#12231), beta-actin (Cell Signalling \#4967S) antibody or the mouse anti-phospho-H3 antibody (Cell Signaling \#9706) diluted 1:1000 in $50 \mathrm{mM}$ Tris, $\mathrm{pH} 7.2,150 \mathrm{mM} \mathrm{NaCl}, 0.1 \%$ Tween, then washed twice for $15 \mathrm{~min}$ with $50 \mathrm{mM}$ Tris, $\mathrm{pH}$ 7.2, $150 \mathrm{mM} \mathrm{NaCl}, 0.1 \%$ Tween and incubated for $1 \mathrm{~h}$ at room temperature with horseradish peroxidase-conjugated secondary antibodies (GE Healthcare) diluted 1:10000 in $50 \mathrm{mM}$ Tris, $\mathrm{pH} 7.2,150 \mathrm{mM} \mathrm{NaCl}, 0.1 \%$ Tween. 
After three final 5 min washes with $50 \mathrm{mM}$ Tris, $\mathrm{pH} 7.2,150 \mathrm{mM} \mathrm{NaCl}, 0.1 \%$ Tween, membranes were processed with ECL Prime (GE Healthcare; \#RPN2232) for signal detection. Protein levels were determined by quantifying pixel intensity for each band of interest relative to pixel intensity of the actin band in the same sample.

\subsubsection{Cell culture and extract preparation}

Cell culture media, serum and antibiotics were purchased from Invitrogen. HeLa and A375 cells were cultured in DMEM + Glutamax supplemented with $10 \%$ FCS, 100 units/mL penicillin (G sodium salt) and $100 \mu \mathrm{g} / \mathrm{mL}$ streptomycin at $37^{\circ} \mathrm{C}$ in an atmosphere containing $5 \% \mathrm{CO}_{2}$. Cell extracts were prepared in PBS lysis buffer $\mathrm{pH}$ 7.4, $150 \mathrm{mM} \mathrm{NaCl}, 0.2 \%$ NP40, $1 \mathrm{mM}$ EDTA, $2 \mathrm{mM}$ PMSF, Complete ${ }^{\mathrm{TM}}$ protease inhibitors (Roche), and normalized following spectrophometric dosage at $280 \mathrm{~nm}$.

\subsubsection{CDK1/Cyclin B1 and CDK2/Cyclin A protein expression and purification}

Recombinant active GST-CDK1/Cyclin B1 and GST-CDK2/Cyclin A complexes were prepared as described previously in references ${ }^{16,17}$. Recombinant GST-CDK1, GST-CIV, GSTCDK2/CIV, MBP-Cyclin B and 6His-Cyclin A were expressed in E. coli (BL21 DEA3) following induction with $1 \mathrm{mM}$ isopropyl $\beta$-D-1-thiogalactopyranoside (IPTG) overnight at $20^{\circ} \mathrm{C}$. GST-CDK1, GST-CIV and GST-CDK2/CIV were purified by FPLC on a GSTrap HP $5 \mathrm{~mL}$ column (GE Healthcare) equilibrated in PBS buffer (50 mM phosphate, $\mathrm{pH}$ 7.4, $150 \mathrm{mM}$ $\mathrm{NaCl})$. GST-tagged proteins were eluted with PBS buffer containing glutathione $(50 \mathrm{mM}$; Euromedex), and then further injected onto a desalting column (GE Healthcare) equilibrated in their purification buffer to eliminate free glutathione. MBP-Cyclin B was purified by FPLC on a MBPTrap HP $5 \mathrm{~mL}$ column (GE Healthcare) equilibrated in PBS buffer (50 mM phosphate, pH 7.4, $150 \mathrm{mM} \mathrm{NaCl}$ ). MBP-Cyclin B was eluted with PBS buffer containing $20 \mathrm{mM}$ maltose, and then further injected onto a HiLoad 16/600 Superdex 75 prep-grade column (GE 
Healthcare) equilibrated in PBS buffer. Active GST-CDK1/MBP-Cyclin B complex was formed following individual purification of each subunit and stoichiometric incubation together with GST-CIV. Active GST-CDK2/6His-Cyclin A complex was formed by incubating 6HisCyclin A with GST-CDK2/CIV on the GST affinity column, prior to elution.

\subsubsection{In vitro kinase activity assays}

Kinase assays were performed by incubating CNT-biosensor conjugates, peptide biosensor or control CNTs with either catalytically active recombinant CDK1/Cyclin B1, CDK2/Cyclin A, or HeLa cell extracts as a source of active kinase, in the presence or absence of CDK inhibitor Roscovitine (Euromedex). Fluorescence kinase assays were performed as described previously in references ${ }^{16,17}$ in 96-well plates in a chamber thermostated at $30^{\circ} \mathrm{C}$ using a Clariostar spectrofluorimeter (BMG). The fluorescence of rhodamine-labelled peptide biosensor or CNTbiosensor conjugate was monitored over time in $200 \mu \mathrm{L}$ PBS (Sigma) supplemented with $5 \mathrm{mM}$ $\mathrm{MgCl}_{2}, 0.5 \mathrm{mM} \mathrm{ATP}$ at $605 \mathrm{~nm}$ following excitation at $550 \mathrm{~nm}$. In all experiments, relative fluorescence was calculated following substraction of biosensor fluorescence (peptide alone or CNT-peptide conjugate) from fluorescence values obtained upon incubation with kinase. Data analysis was performed using the GraFit 7 Software (Erathicus Ltd). Experiments were performed in triplicate, and error bars indicate standard deviation from average.

\subsubsection{Cell internalization studies, fluorescence imaging and quantification}

Fluorescently labelled-biosensor peptide or CNT-biosensor conjugates were overlaid on living cells grown to subconfluency on glass coverslips for $20 \mathrm{~min}$ at the indicated concentrations in $\mathrm{H}_{2} \mathrm{O} /$ glucose, and cells were then replaced in cell culture medium supplemented with serum for recovery for 30-45 min. Cells were extensively washed with PBS, stained with Hoechst, fixed with formalin and mounted in Mowiol. Cells were imaged with a Zeiss Axioimager Z2 microscope equipped with a CoolSnap HQ2 camera and piloted by MetaMorph software. 
Image $\mathbf{J}$ was then used for image analysis and quantification of signals. Regions of interest (ROI) corresponding to $10-15$ cells in which fluorescence appeared homogeneous were designed and the mean grey levels of fluorescence for each channel (Hoechst and rhodamine) were quantified within these ROIs. For each experiment, and the mean ratiometric value of rhodamine/Hoechst was calculated from 3-4 different ROIs.

\subsubsection{Cell viability studies}

Cell viability was evaluated by crystal violet staining at $0,24 \mathrm{~h}$ and $48 \mathrm{~h}$ as follows: cells were washed with PBS, fixed with $3.7 \%$ formaldehyde for $10 \mathrm{~min}$ and then incubated with $0.1 \%$ crystal violet dye for 30 min. After rinsing, crystals were dissolved in $10 \%$ acetic acid and viability was determined by measuring absorbance at $595 \mathrm{~nm}$.

\subsection{In vivo fluorescence imaging and cancer mouse models}

Animal experimentations were performed in accordance with the institutional guidelines of the European Community (EU Directive 2010/63/EU) for the use of experimental animals and received the approval of the local ethics committee (Cometh38 Grenoble, France) and the French Ministry of Higher Education and Research under the reference: apafis\#8854$2017031314338357 \mathrm{v} 1$.

\subsubsection{Cancer mouse model}

CNT-peptide conjugates were injected into mice bearing subcutaneous xenografts established from A375 melanoma cell line which express hyperactive forms of cyclin-dependent kinases. Five-week-old female NMRI nude mice (Janvier Labs, Le Genest-Saint Isle, France) were anesthetized (4\% isoflurane/air for anesthesia induction and $1.5 \%$ thereafter) and were injected subcutaneously in the flank with $3 \times 10^{6}$ exponentially dividing A375 cells ( $200 \mu \mathrm{L}$ in $1 \mathrm{X}$ PBS). Tumor size was measured twice a week using a caliper. 


\subsubsection{CNT-peptide preparation for in vivo administration}

CNT-peptide conjugates were dispersed in water/glucose 5\% to reach a CNT concentration of $1 \mathrm{~g} / \mathrm{L}$ before the solution was submitted to two sonication steps of $10 \mathrm{~min}$ and $5 \mathrm{~min}$ interspersed with 1 min of vortex agitation. It was then diluted in water/glucose $5 \%$ to reach the desired concentrations.

\subsubsection{In vivo fluorescence imaging in mice}

In vivo fluorescence imaging was performed using IVIS Kinetic (PerkinElmer, USA) with $640 \pm 15 \mathrm{~nm}$ excitation and 680 $\pm 10 \mathrm{~nm}$ emission filter, Fluobeam700 (Fluoptics, France) with $680 \mathrm{~nm}$ excitation and >700 nm long pass filter and Fluobeam800 (Fluoptics, France) with $780 \mathrm{~nm}$ excitation and $>830 \mathrm{~nm}$ long pass filter for the detection of Cy5, Alexa750 and Dy755 respectively.

In vivo biodistribution, pharmacokinetics and elimination pathways of CNT conjugates were characterized by fluorescence imaging in mice. Six weeks old NMRI female nude mice (Janvier labs, France) were anesthetized (air/isoflurane $4 \%$ for induction and $1.5 \%$ thereafter) and whole-body fluorescence imaging was performed before, and at several time points after CNT-peptide conjugate administration. Mice were sacrificed at the final time point and organs were harvested for ex vivo fluorescence imaging. Organs from control mice were also exposed to the camera to set the autofluorescence level for each organ. For in vivo image analyses, ROIs were defined on the tumor and contralateral site (skin) as well as on the liver and kidney areas. For ex vivo image analyses, ROIs were adjusted on each tissue sample. Results were expressed as average fluorescence in the ROIs (average radiant efficiency $\left[\mathrm{p} / \mathrm{s} / \mathrm{cm}^{2} / \mathrm{sr}\right] /\left[\mu \mathrm{W} / \mathrm{cm}^{2}\right]$ ) and graphs represent the mean \pm SEM for 6 mice. 
4.3.4. Noninvasive fluorescence imaging of CDK biosensor activation in tumor-bearing mice

Eighteen days after A375 melanoma tumor implantation, CNT-CDKACT1-Cy5 and CNTNanoCtrl-Dy755 conjugates were co-injected into the tumor $(25 \mu \mathrm{L}$ at $10 \mu \mathrm{M}$ each $)$ and dual fluorescence imaging at suitable wavelengths was performed immediately after injection (Ti), then $1 \mathrm{~h}$ and $2 \mathrm{~h}$ post-injection. Biosensor fluorescence was imaged and quantified with respect to control peptide fluorescence. At each imaging time point, CNT-biosensor/CNT-control conjugate fluorescence ratio was calculated (CNT-CDKACT1-Cy5/CNT-NanoCtrl-Dy755) and expressed as a percentage of the Ti ratio obtained immediately after the injection.

4.3.5. Modulation of CDK activity in vivo in tumor-bearing mice evidenced by non-invasive fluorescence imaging

When A375 melanoma subcutaneous tumors reached a volume of about $250 \mathrm{~mm}^{3}$, mice were treated by intraperitoneal injection of Roscovitine $(50 \mathrm{mg} / \mathrm{kg})$ and $\mathrm{RO}-3306$ (4 mg/kg) or vehicle (30\% DMSO; 25\% Diluent (Tween 80, n-n diméthylacétamide, PEG 400 (proportion : 1-2-7) and $45 \%$ PBS) one day and $1 \mathrm{~h}$ before injection of nanosensor 9 in the tumor (50 $\mu \mathrm{L}$ at $9 \mu \mathrm{M})$. Dual fluorescence imaging at suitable wavelengths was performed immediately after injection (Ti), then $30 \mathrm{~min}, 1 \mathrm{~h}$ and $2 \mathrm{~h}$ post-injection. At each imaging time point, Cy5/Alexa750 fluorescence ratio was calculated and expressed as a percentage of the Ti ratio obtained immediately after the injection.

\section{Supporting Information}

Supporting Information is available from the Wiley Online Library or from the author.

\section{Acknowledgements}

We thank Alexane Caignard for help with the preparation of one CNT conjugate. We thank C. Royer and V. Demais for help with TEM analyses at the "Plateforme Imagerie in vitro" at the 
Center of Neurochemistry (INCI, Strasbourg, France). We thank Jean-Luc Coll for critical reading of the manuscript.

Funding: This work was supported by the CNRS (Centre National de la Recherche Scientifique) and a grant from the French National Research Agency (ANR) (NANOMULTISENS Project Grant NANR-13-BS10-0003). C.-M.T. and B.D. were funded by the ANR. We acknowledge the MRI imaging facility (Montpellier, France), a member of the national infrastructure France-BioImaging supported by the French National Research Agency (ANR-10-INBS-04, Investissements d'avenir). The Optimal imaging platform is supported by France Life Imaging (French program "Investissement d'Avenir" grant; "Infrastructure d'avenir en Biologie Santé", ANR-11-INBS-0006) and the IBISA French consortium "Infrastructures en Biologie Santé et Agronomie". This work was partly supported by the ANR through the LabEx project Chemistry of Complex Systems (ANR-10-LABX0026_CSC), and by the International Center for Frontier Research in Chemistry (icFRC).

Author Contributions: B.D. performed experiments involving conjugation and purification of CNT-peptide biosensors. C.-M.T., M.P. and S.D. performed peptide biosensor labelling, purification and characterization, recombinant protein kinase expression and purification, in vitro kinase assays, cell culture and cell extract preparation, fluorescence microscopy studies of nanobiosensor internalization and quantification in living cells. M.G., J.V. \& V.J. prepared animals, xenografts and performed animal imaging studies. M.C.M, C.M-M., A.B. \& V.J. supervised the project and wrote the manuscript.

Competing Interests: The authors declare no competing interests.

Author 1 and Author 2 contributed equally to this work.

Received: ((will be filled in by the editorial staff)) Revised: ((will be filled in by the editorial staff)) Published online: ((will be filled in by the editorial staff)) 


\section{References}

[1] D. Fabbro, S. W. Cowan-Jacob, H. Moebitz, Br. J. Pharmacol. 2015, 172, 2675.

[2] E. D. Fleuren, L. Zhang, J. Wu, R. J. Daly, Nat. Rev. Cancer 2016, 16, 83.

[3] S. Lim, P. Kaldis, Development 2013, 140, 3079.

[4] M. Malumbres, M. Barbacid, Trends Biochem. Sci. 2005, 30, 630.

[5] M. Malumbres, M. Barbacid, Nat. Rev. Cancer 2001, 1, 222.

[6] M. Malumbres, M. Barbacid, Curr. Opin. Gen. Dev. 2007, 17, 60.

[7] M. Malumbres, M. Barbacid, Nat. Rev. Cancer 2009, 9, 153.

[8] S. Lapenna, A. Giordano, Nat. Rev. Drug Discov. 2009, 8, 547.

[9] U. Asghar, A. K. Witkiewicz, N. C. Turner, E. S. Knudsen, Nat. Rev. Drug Discov. 2015, $14,130$.

[10] D. Santamaría, C. Barrière, A. Cerqueira, S. Hunt, C. Tardy, K. Newton, J. F. Cáceres, P. Dubus, M. Malumbres, M. Barbacid, Nature 2007, 448, 811.

[11] D. O. Morgan, Annu. Rev. Cell Dev. Biol. 1997, 13, 261.

[12] T. N. N. Van, M. C. Morris, Prog. Mol. Biol. Transl. Sci. 2013, 113, 217.

[13] M. C. Morris, ACS Chem. Med. Lett. 2014, 5, 99.

[14] A. E. Palmer, Y. Qin, J. G. Park, J. E. McCombs, Trends Biotechnol. 2011, 29, 144.

[15] J. A. González-Vera, M. C. Morris, Proteomes 2015, 3, 369.

[16] T. N. N. Van, S. Lykaso, M. Pellerano, M. C. Morris, ChemBioChem 2014, 15, 2298.

[17] C. Prével, C. M. Pellerano, J. A. González-Vera, P. Henri, L. Meunier, J. Vollaire, V. Josserand, M. C. Morris, Biosens. Bioelectron. 2016, 85, 371.

[18] M. Peyressatre, A. Laure, M. Pellerano, H. Boukhaddaoui, I. Soussi, M. C. Morris, Biotechnology J. 2020, 15, 1900474.

[19] C. J. Serpell, K. Kostarelos, B. G. Davis, ACS Cent. Sci. 2016, 2, 190.

[20] N. Panwar, A. M. Soehartono, K. K. Chan, S. Zeng, G. Xu, J. Qu, P. Coquet, K.-T. Yong, X. Chen, Chem. Rev. 2019, 119, 9559. 
[21] K. P. Loh, D. Ho, G. N. C. Chiu, D. T. Leong, G. Pastorin, E. K.-H. Chow, Adv. Mater. 2018, 30, 1802368.

[22] D. Chen, C. A. Dougherty, K. Zhu, H. Hong, J. Control. Release 2015, 210, 230.

[23] B.-P. Jiang, B. Zhou, Z. Lin, H. Liang, X.-C. Shen, Chem. Eur. J. 2019, 25, 3993.

[24] C.-M. Tîlmaciu, M. C. Morris, Front. Chem. 2015, 3, 59.

[25] S. Kumar, R. Rani, N. Dilbaghi, K. Tankeshwar, K.-H. Kim, Chem. Soc. Rev. 2017, 46, 158.

[26] B. Pei, W. Wang, N. Dunne, X. Li, Nanomaterials 2019, 9, 1501.

[27] G. Lamanna, A. Battigelli, C. Ménard-Moyon, A. Bianco, Nanotechnol. Rev. 2012, 1, 17.

[28] L. Chio, J. T. Del Bonis-O'Donnell, M. A. Kline, J. H. Kim, I. R McFarlane, R. N. Zuckermann, M. P. Landry, Nano Lett. 2019, 19, 7563.

[29] J. T. Wang, R. Klippstein, M. Martincic, E. Pach, R. Feldman, M. Šefl, Y. Michel, D. Asker, J. K. Sosabowski, M. Kalbac, T. Da Ros, C. Ménard-Moyon, A. Bianco, I. Kyriakou, D. Emfietzoglou, J.-C. Saccavini, B. Ballesteros, K. T. Al-Jamal, G. Tobias, ACS Nano 2020, 14, 129.

[30] H. Kafa, J. T.-W. Wang, N. Rubio, R. Klippstein, P. M. Costa, H. A. F. M. Hassan, J. K. Sosabowski, S. S. Bansal, J. E. Preston, N. J. Abbott, K. T. Al-Jamal, J. Control. Release 2016, $225,217$.

[31] K. T. Al-Jamal, H. Nerl, K. H. Müller, H. Ali-Boucetta, S. Li, P. D. Haynes, J. R. Jinschek, M. Prato, A. Bianco, K. Kostarelos, A. E. Porter Nanoscale 2011, 3, 2627.

[32] B. Dinesh, A. Bianco, C. Ménard-Moyon, Nanoscale 2016, 8, 18596.

[33] H. Ali-Boucetta, A. Nunes, R. Sainz, M. A. Herrero, B. Tian, M. Prato, A. Bianco, K. Kostarelos, Angew. Chem. Int. Ed. 2013, 52, 2274.

[34] D. A. Heller, P. V. Jena, M. Pasquali, K. Kostarelos, L. G. Delogu, R. E. Meidl, S. V. Rotkin, D. A. Scheinberg, R. E. Schwartz, M. Terrones, Y.H. Wang, A. Bianco, A. A. Boghossian, S. Cambré, L. Cognet, S. R. Corrie, P. Demokritou, S. Giordani, T. Hertel, T. 
Ignatova, M. F. Islam, N. M. Iverson, A. Jagota, D. Janas, J. Kono, S. Kruss, M. P. Landry, Y. Li, R. Martel, S. Maruyama, A. V. Naumov, M. Prato, S. J. Quinn, D. Roxbury, M. S. Strano, J. M. Tour, R. B. Weisman, W. Wenseleers, M. Yudasaka, Nat. Nanotechnol. 2020, 15, 164.

[35] O. Gavet, J. Pines, Dev. Cell. 2010, 18, 533.

[36] J. V. Frangioni, Curr. Opin. Chem. Biol. 2003, 7, 626.

[37] L. Kurzawa, M. Pellerano, J. B. Coppolani, M. C. Morris, PLoS One 2011, 6, e2655.

[38] I. Marangon, C. Ménard-Moyon, J. Kolosnjaj-Tabi, M. L. Béoutis, L. Lartigue, D. Alloyeau, E. Pach, B. Ballesteros, G. Autret, T. Ninjbadgar, D. F. Brougham, A. Bianco, F. Gazeau, Adv. Funct. Mater. 2014, 24, 7173.

[39] R. Singh, D. Pantarotto, L. Lacerda, G. Pastorin, C. Klumpp, M. Prato, A. Bianco, K. Kostarelos, PNAS 2006, 103, 3357.

[40] L. T. Vassilev, Cell Cycle 2006, 5, 2555. 
A

B

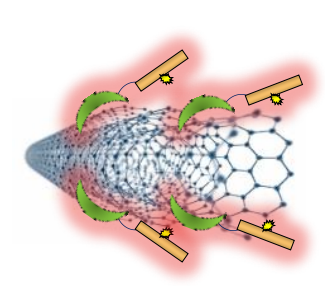

C
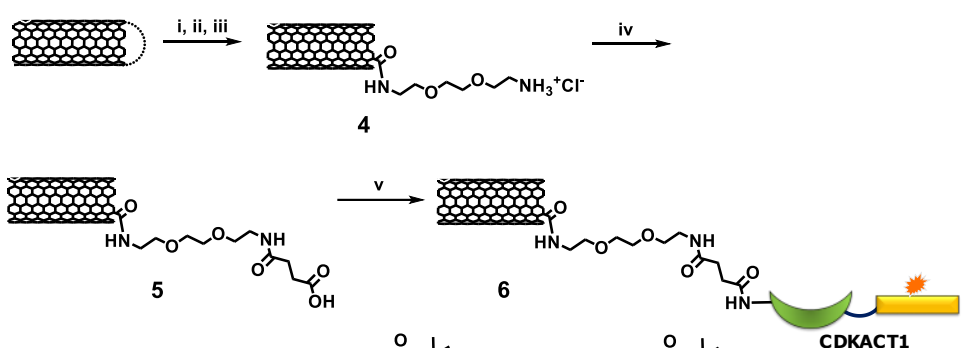

D
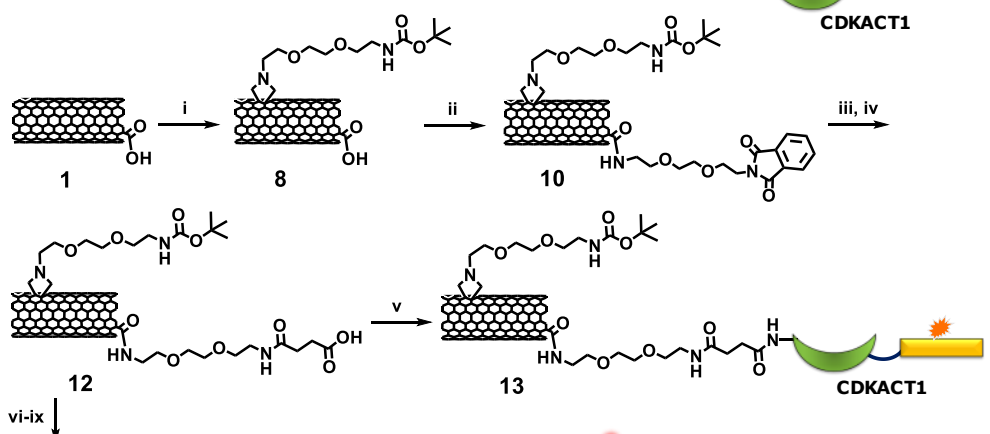

vi-ix

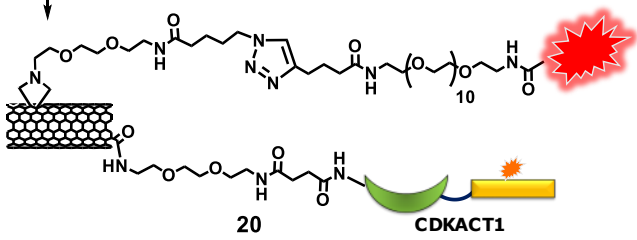

Figure 1. CDKACT1 Biosensor and multifunctionalized nanobiosensor.

(A) Schematic representation of CDKACT1-Rhoda peptide biosensor. This bipartite design comprises a phosphoamino acid binding domain (PAABD) and a substrate derived from Cyclin B1. Rhodamine was conjugated onto the unique cysteine proximal to the phosphorylation site (at position -2). Upon phosphorylation of the substrate moiety by active CDK1 kinase, the PAABD recognizes the phosphorylated sequence. The interaction between the PAABD and the substrate changes the local environment of rhodamine, consequently promoting fluorescence enhancement. (B) CDK1 Nanobiosensor prepared through multifunctionalization of CDKACT1-Rhoda on MWCNTs. (C) Synthesis of $f$-MWCNTs 6: i) $\mathrm{H}_{2} \mathrm{SO}_{4} / \mathrm{HNO}_{3}(3: 1)$, sonication, 24 h; ii) a) oxalyl chloride, reflux, 24 h; b) Boc-monoprotected TEG diamine 2, THF, reflux, $48 \mathrm{~h}$; iii) $4 \mathrm{M} \mathrm{HCl}$ in 1,4-dioxane, $6 \mathrm{~h}$; iv) $N, N$-diisopropylethylamine (DIEA), succinic anhydride, $\mathrm{CH}_{2} \mathrm{Cl}_{2}, 1$ day; v) a) $N$-(3-dimethylaminopropyl)- $N$ '-ethylcarbodiimide hydrochloride (EDC. $\mathrm{HCl}$ ), NHS, DMF, $24 \mathrm{~h}$; b) peptide, $\mathrm{H}_{2} \mathrm{O} / \mathrm{CH}_{3} \mathrm{CN}, 16 \mathrm{~h}$. (D) Synthesis of $f$-MWCNTs 13 and 20: i) paraformaldehyde, 7, DMF, $125^{\circ} \mathrm{C}, 2$ days; ii) $\mathrm{EDC} \cdot \mathrm{HCl}, \mathrm{DIEA}, 9$, DMF, 24 h; iii) hydrazine, ethanol, 6 h; iv) succinic anhydride, DIEA, $\mathrm{CH}_{2} \mathrm{Cl}_{2}, 1$ day; v) a) 
EDC. $\mathrm{HCl}$, NHS, DMF, $24 \mathrm{~h}$; b) peptide, $\mathrm{H}_{2} \mathrm{O} / \mathrm{CH}_{3} \mathrm{CN}, 16 \mathrm{~h}$. vi) $4 \mathrm{M} \mathrm{HCl}$ in 1,4-dioxane, $6 \mathrm{~h}$; vii) 5-azidopentanoic acid, EDC· $\mathrm{HCl}$, hydroxybenzotriazole (HOBt), DIEA, DMF, 1 day; viii) 16, $\mathrm{CuSO}_{4} .5 \mathrm{H}_{2} \mathrm{O}$, sodium ascorbate, $\mathrm{H}_{2} \mathrm{O} / \mathrm{MeOH}, 2$ days; ix) a) EDC. $\mathrm{HCl}$, NHS, DMF, $24 \mathrm{~h}$; b) CDKACT1-Cy5 peptide, $\mathrm{H}_{2} \mathrm{O} / \mathrm{CH}_{3} \mathrm{CN}, 16 \mathrm{~h}$. 
$\mathrm{A}$ $\mathrm{CDKl} / \mathrm{Cyclin} \mathrm{B}$

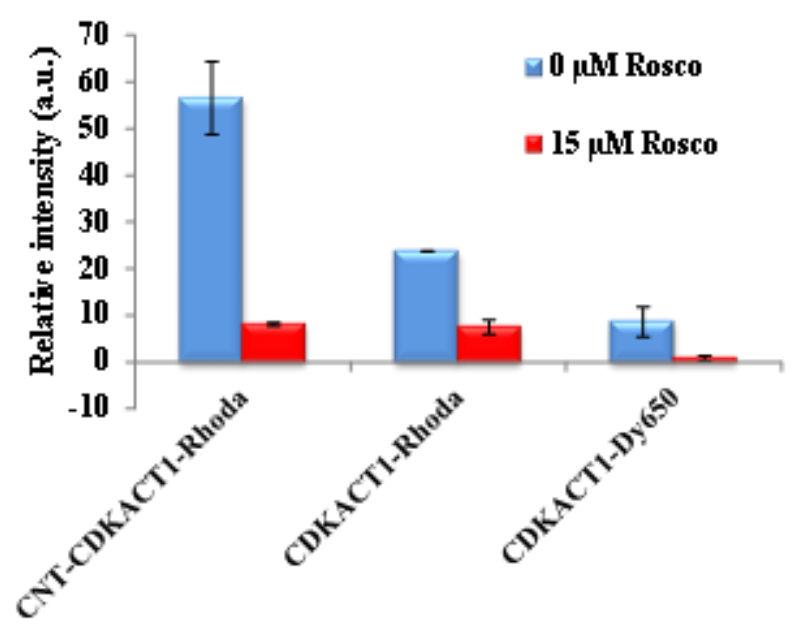

$\mathrm{C}$

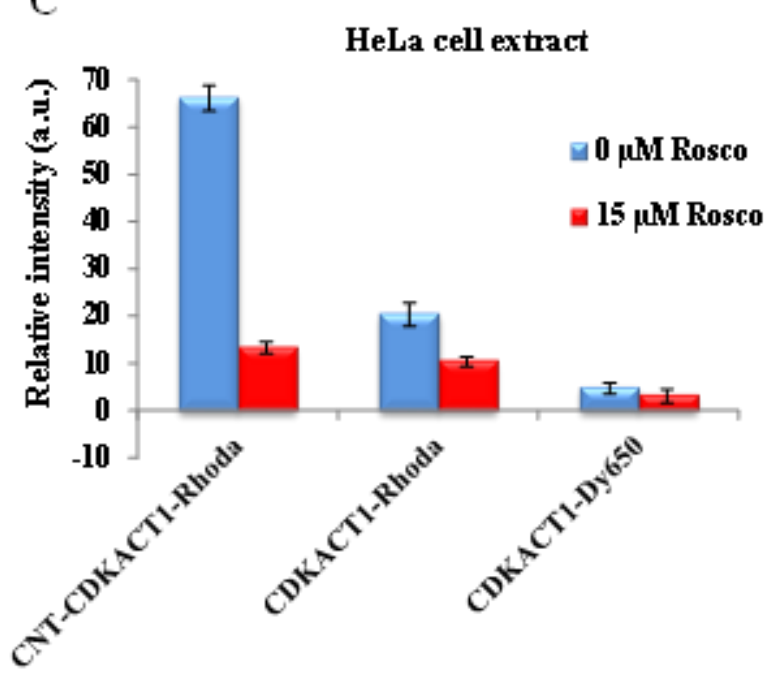

B $\quad$ CDK2/Cyclin A

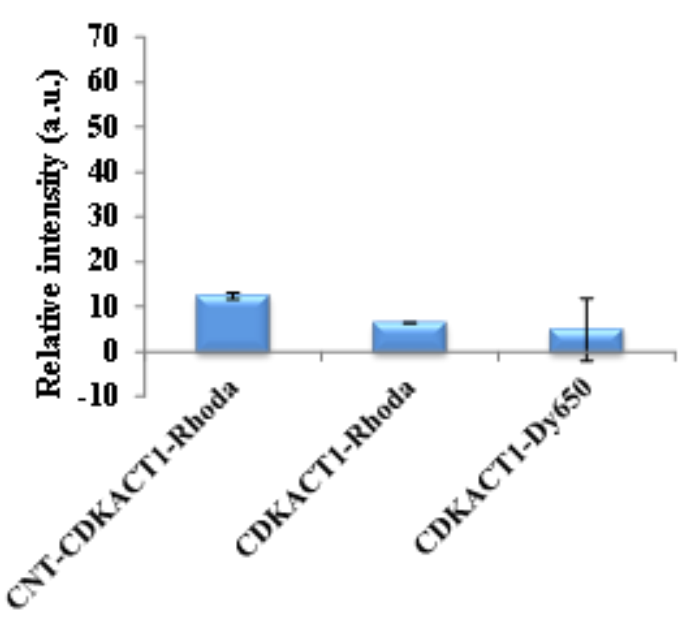

Figure 2. Response of CNT-CDKACT1-Rhoda to CDK1 and CDK2 kinase activity in vitro (A) Response of $250 \mathrm{nM}$ CNT-CDKACT1-Rhoda to $75 \mathrm{nM}$ recombinant CDK1/Cyclin B1 with or without $5 \mu \mathrm{M}$ Roscovitine. (B) Response of $250 \mathrm{nM}$ CNT-CDKACT1-Rhoda to $100 \mathrm{nM}$ recombinant CDK2/Cyclin A. (C) Response of $250 \mathrm{nM}$ CNT-CDKACT1-Rhoda to $40 \mu \mathrm{g}$ HeLa cell extract with or without $5 \mu \mathrm{M}$ Roscovitine. 
A

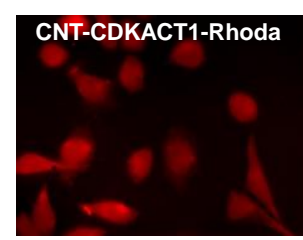

CDKACT1-Rhoda

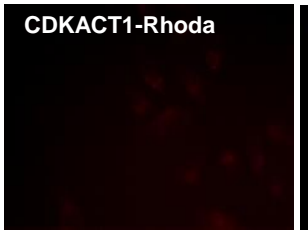

B CNT-CDKACT1-Rhoda
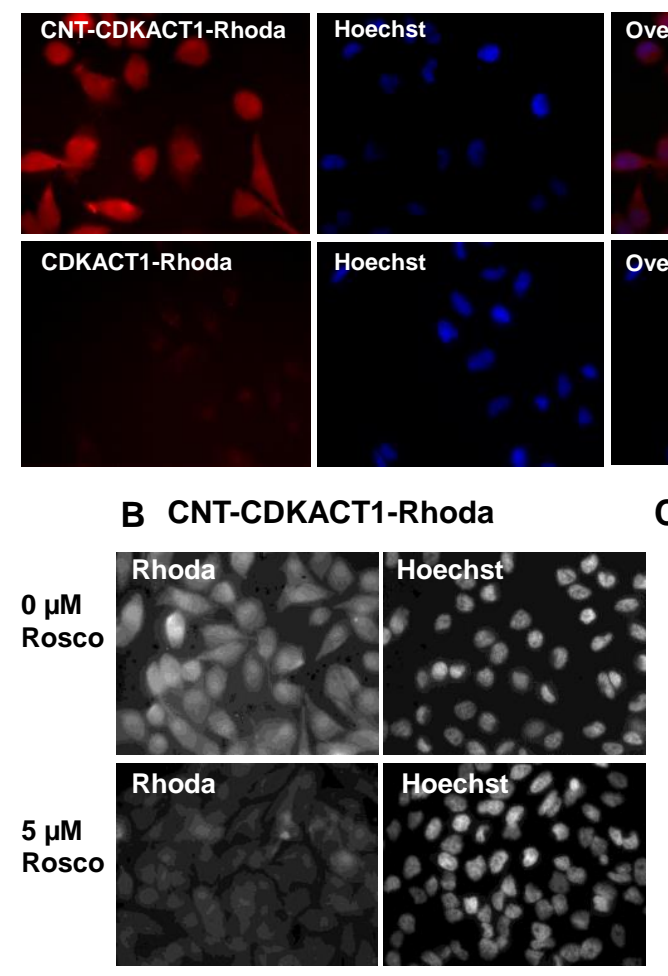

D

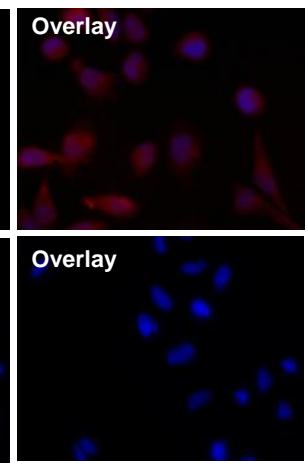

C CDKACT1-Rhoda (control - no CNT)

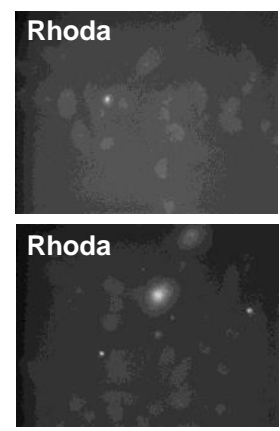

$\square 0 \mu \mathrm{M}$ Roscovitine

$5 \mu \mathrm{M}$ Roscovitine

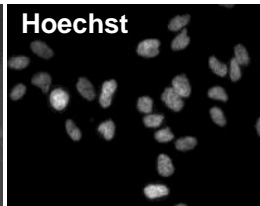

Hoechst

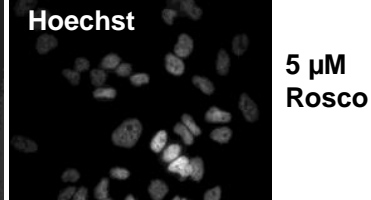

Figure 3. Cellular internalization and response to endogenous CDK kinase activity

(A) 20 min overlay of $0.5 \mu \mathrm{M}$ CNT-CDKACT1-Rhoda (corresponding to $51 \mu \mathrm{g} / \mathrm{mL}$ of CNTs) (upper panels) and CDKACT1-Rhoda (lower panels) on HeLa cells followed by formalin fixation, nuclear staining with Hoechst and fluorescence imaging. (B) Internalization of $0.5 \mu \mathrm{M}$ CNT-CDKACT1-Rhoda overlaid onto HeLa cells as described in (A) following mock treatment or treatment with $5 \mu \mathrm{M}$ Roscovitine for $24 \mathrm{~h}$, fixed with formalin and stained with Hoechst. (C) Overlay of CDKACT1-Rhoda onto HeLa cells as described in (A), following mock treatment or treatment with $5 \mu \mathrm{M}$ Roscovitine for $24 \mathrm{~h}$, fixed with formalin and stained with Hoechst. (D) Ratiometric quantification of CNT-CDKACT1-Rhoda and CDKACT-Rhoda fluorescence in (B) and (C) relative to Hoechst fluorescence. 
a

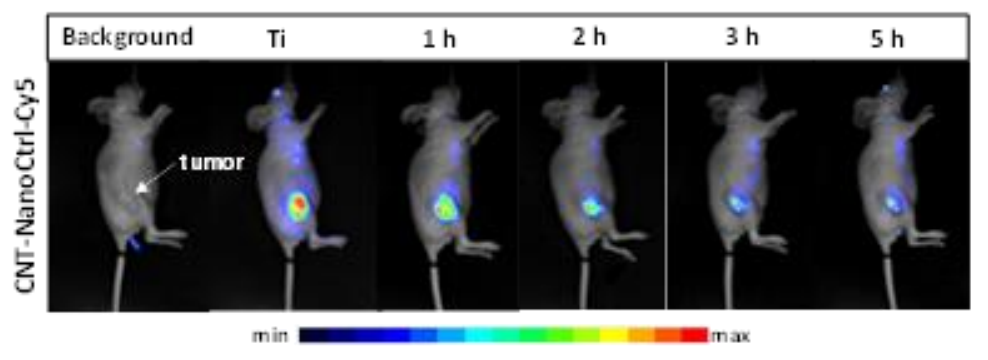

b

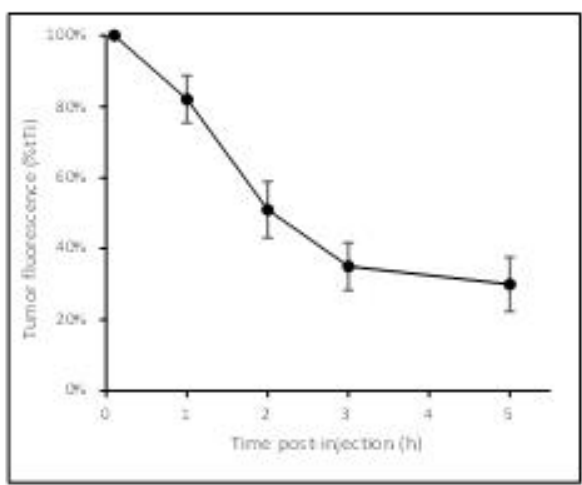

Figure 4. In vivo tumour retention of CNT-NanoCtrl-Cy5 conjugate.

(A) In vivo fluorescence imaging of CNT-NanoCtrl-Cy5 (excitation: $640 \pm 15 \mathrm{~nm}$; signal collection $680 \pm 10 \mathrm{~nm})$ at various time points after intratumoral injection $(100 \mu \mathrm{L}$ at $1 \mu \mathrm{M}$ as quantified by Cy5 fluorescence, corresponding to $5.7 \mu \mathrm{g}$ of functionalized CNTs) in subcutaneous tumour (A375)-bearing mice. (B) Kinetics of tumour fluorescence signals after intratumoral injection of CNT-NanoCtrl-Cy5. Data are represented as the percentage of the signal measured 5 minutes after injection (Ti). 


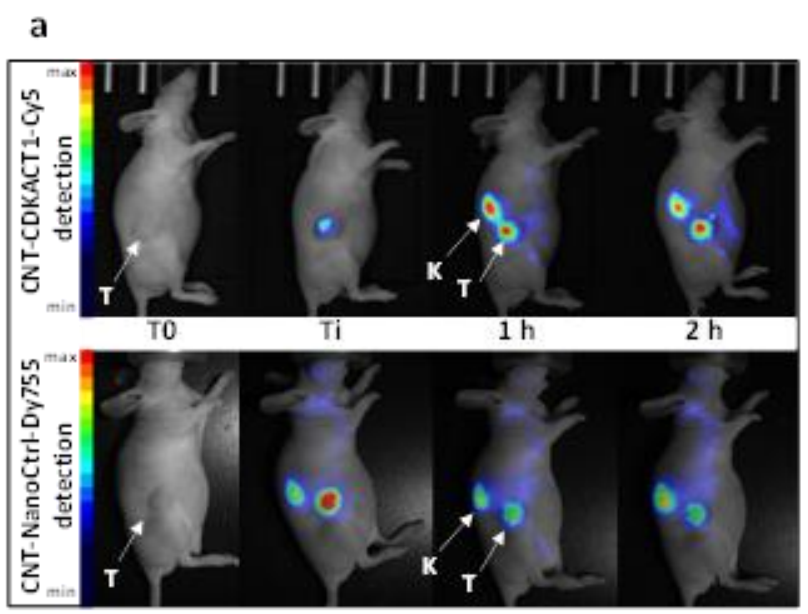

b

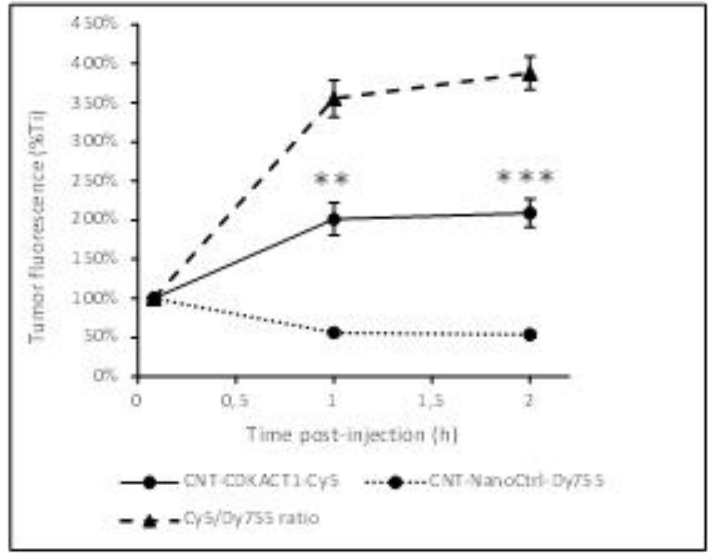

Figure 5. Non-invasive imaging of CDK biosensor fluorescence in tumour-bearing mice.

(A) In vivo dual fluorescence imaging of CNT-CDKACT1-Cy5 (excitation: $640 \pm 15 \mathrm{~nm}$; signal collection: $680 \pm 10 \mathrm{~nm}$ ) and CNT-NanoCtrl-Dy755 (excitation: $780 \mathrm{~nm}$; signal collection: > 830 $\mathrm{nm})$ immediately $\left(\mathrm{T}_{\mathrm{i}}\right), 1 \mathrm{~h}$ and $2 \mathrm{~h}$ after their co-injection in the tumour $(25 \mu \mathrm{L}$ at $10 \mu \mathrm{M}$ each as quantified by the fluorescent probe, corresponding to 8.7 and $14.8 \mu \mathrm{g}$ CNT-CDKACT1-Cy5 and CNT-NanoCtrl-Dy755, respectively). $\mathrm{K}=$ kidney and T = tumour. (B) Kinetics of Cy5 and Dy755 fluorescence signals in the tumour after co-injection of CNT-CDKACT1-Cy5 (solid line) and CNT-NanoCtrl-Dy755 (dotted line) n=7 mice. Statistical analyses: Bonferroni's multiple comparisons test $(* * \mathrm{p}$-value $<0.01$; $* * * \mathrm{p}$-value $<0.001)$. In vivo CDKACT1 biosensor response is reported by Cy5/Dy755 fluorescence ratio in the tumour (dashed line). 
a
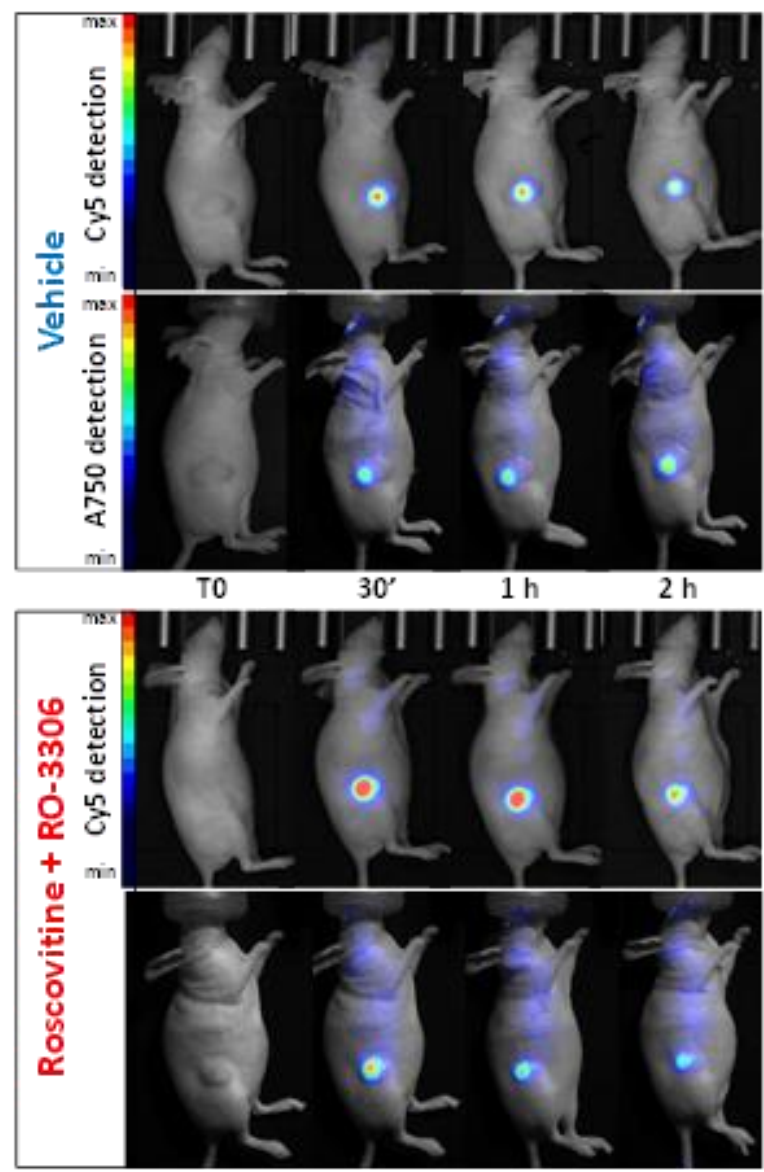

b

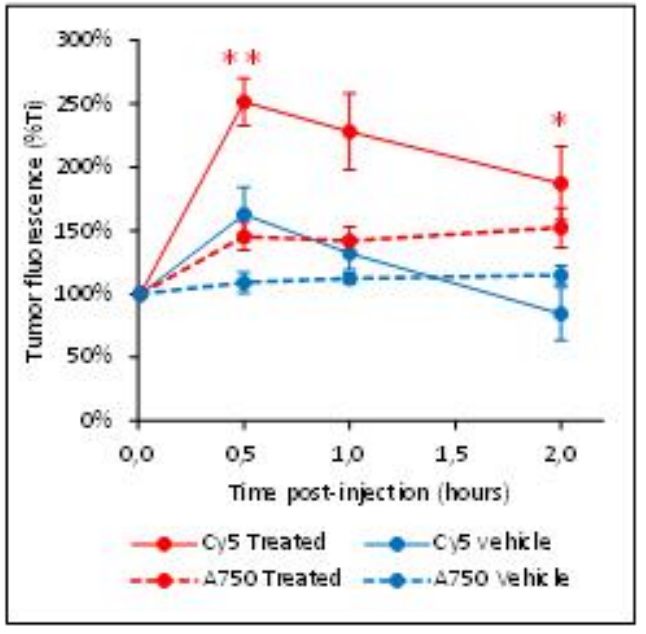

c

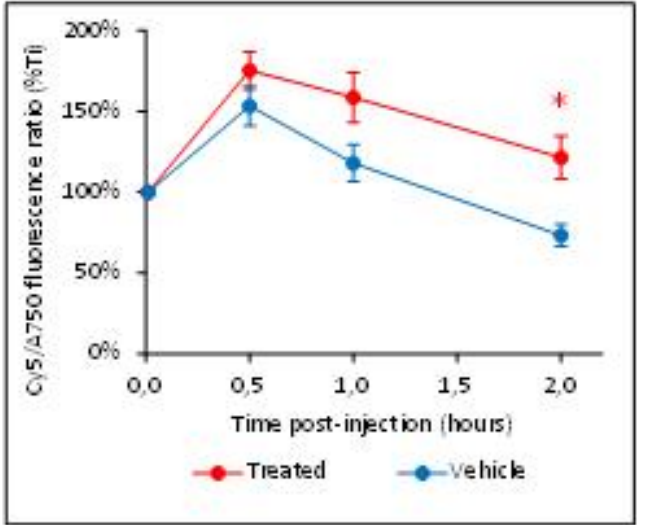

Figure 6. Modulation of CDK activity in vivo in tumour-bearing mice evidenced by noninvasive fluorescence imaging.

In vivo dual fluorescence imaging of tumour-bearing mice (subcutaneous A375 melanoma) treated by intraperitoneal injection of Roscovine $(50 \mathrm{mg} / \mathrm{kg})$ and RO-3306 (4 mg/kg) twice, first for one day and then again for $1 \mathrm{~h}$ before injection of nanobiosensor $\mathbf{2 0}$ in the tumour (50 $\mu \mathrm{L}$ at $9 \mu \mathrm{M}$ as quantified by the absorbance of their fluorescent probe, corresponding to $25 \mu \mathrm{g}$ CNT conjugate). (A) Dual fluorescence imaging was performed using 640 $\pm 15 \mathrm{~nm}$ excitation and $680 \pm 10 \mathrm{~nm}$ for Cy5 detection, and $680 \mathrm{~nm}$ excitation and $>700 \mathrm{~nm}$ emission for Alexa750 detection, immediately $\left(\mathrm{T}_{\mathrm{i}}\right), 30 \mathrm{~min}, 1 \mathrm{~h}$ and $2 \mathrm{~h}$ after nanobiosensor 20 injection. (B) Kinetics of Cy5 (solid lines) and Alexa750 (dotted lines) fluorescence emission in the tumour after nanobiosensor $\mathbf{2 0}$ injection in treated (red lines) or non-treated (blue lines) mice. $\mathrm{n}=8$ mice per group. Statistical analyses: Bonferroni's multiple comparisons test $(* \mathrm{p}$-value $<0.05$; **p- 
value $<0.01$ ). (C) In vivo nanobiosensor 20 response in treated (red line) or non-treated (blue line) mice determined by Cy5/Alexa750 fluorescence ratio. $n=8$ mice per group. Statistical analyses: Bonferroni's multiple comparisons test $(* \mathrm{p}$-value $<0.05)$. 


\section{Table of contents}

Nanobiosensor Reports on CDK1 Kinase Activity in Tumor Xenografts in Mice

A nanobiosensor of the mitotic kinase CDK1 was engineered through multifunctionalization of carbon nanotubes with a CDK1-specific fluorescent peptide reporter. This CNT-fluorescent peptide conjugate reports on CDK1 activity in a sensitive and dose-dependent fashion in cell extracts, in living cells and within tumor xenografts in mice by fluorescence imaging.

\section{Graphical Abstract}

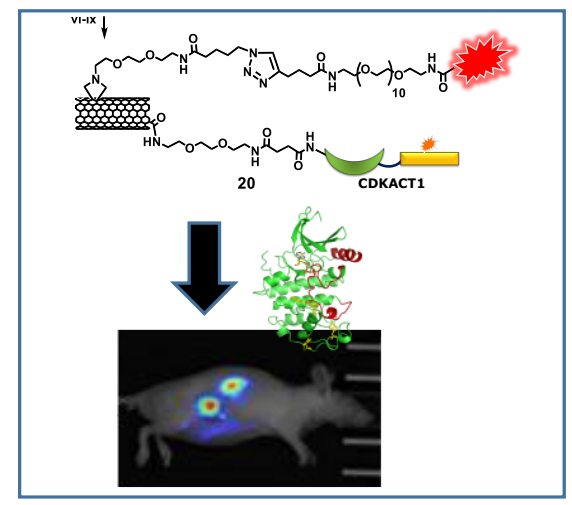




\section{Supporting Information}

\section{Nanobiosensor reports on CDK1 kinase activity in tumor xenografts in mice}

Carmen Mihaela Tîlmaciu ${ }^{1} \%$, Bhimareddy Dinesh ${ }^{2} \%$, Morgan Pellerano ${ }^{1}$, Sebastien Diot ${ }^{1}$, Mélanie Guidetti ${ }^{3}$, Julien Vollaire ${ }^{3}$, Alberto Bianco ${ }^{2}$, Cécilia Ménard-Moyon ${ }^{2}{ }^{*}$, Véronique Josserand $^{3 *}$, May C. Morris ${ }^{1 *}$

\section{Supplementary Materials and Methods}

The linkers tert-butyl (2-(2-(2-aminoethoxy)ethoxy)ethyl)carbamate $\quad \mathbf{2}, \quad\{2-[2-(2-t e r t-$ butoxycarbonylaminoethoxy)ethoxy]ethylamino $\}$ acetic acid 7, and 2-(2-(2-(2aminoethoxy)ethoxy)ethyl)isoindoline-1,3-dione 9 were synthesized using protocols described in reference [1]. The Kaiser test was performed to estimate the amine loadings according to the procedure described in reference [2]. The UV/Vis spectra were recorded on a Varian Cary 5000 spectrophotometer. ${ }^{1} \mathrm{H}$ and ${ }^{13} \mathrm{C}$ NMR spectra were recorded on Bruker $400 \mathrm{MHz}$ instrument. The peak values were obtained as ppm and referenced to the solvent. The resonance multiplicity is described as s (singlet), $\mathrm{t}$ (triplet), $\mathrm{m}$ (multiplet), and bs (broad singlet). Coupling constants (J) are given in Hz. Thin layer chromatography was performed on aluminum sheets coated with silica gel 60 F254 (Merck, Darmstadt). LC-MS analyses were performed either on a Thermo Fisher Finnigan LCQ Advantage Max system (EC 100/2 Nucleodur 100-3 C18ec column) or a Thermo Scientific Accela UHPLC (Hypers II GOLD column, 50×2.1 mm, $1.9 \mu \mathrm{m}$ ) integrated with a Thermo Scientific LCQ Fleet ion-trap. The mass spectra were deconvoluted using MagTran software 1.03b2 (Amgen, Thousand Oaks, CA). Chromatographic purification was done using Merck silica gel (Kieselgel 60, 40-60 $\mu \mathrm{m}, 230-400$ mesh ASTM). High-performance liquid chromatography (HPLC) analyses were performed either on a Waters e2695 separations module instrument equipped with an autosampler and 2998 PDA detector or on a Varian ProStar 240 instrument equipped with a ProStar 410 autosampler and a ProStar 330 PDA detector, both using a $\mathrm{C}_{18}$ column (EC 150/4.6 Nucleosil 100 or Macherey-Nagel Nucleodur 100-3); gradient: 5-65\% solvent $\mathrm{B}$ in $20 \mathrm{~min}$; eluents: $\mathrm{A}: \mathrm{H}_{2} \mathrm{O}+0.1 \%$ trifluoroacetic acid (TFA); $\mathrm{B}: \mathrm{CH}_{3} \mathrm{CN}+0.08 \%$ TFA. TEM analysis was performed on a Hitachi $\mathrm{H} 7500$ microscope (Tokyo, Japan) with an accelerating voltage of $80 \mathrm{kV}$, equipped with an AMT Hamamatsu camera (Tokyo, Japan). To prepare the TEM grids, the CNT conjugates were dispersed in deionized water and ethanol (1:1) by sonication, deposited onto carbon-coated copper TEM 
grids (Formvar/Carbon 300 Mesh; Cu from Delta Microscopies) and dried under ambient conditions. The thermogravimetric analyses were performed using a Mettler Toledo TGA1 instrument using platinum pans and lids with a ramp of $10^{\circ} \mathrm{C} \cdot \mathrm{min}^{-1}$ under $\mathrm{N}_{2}$ with a flow rate of $50 \mathrm{~mL} \cdot \mathrm{min}^{-1}$ from 100 to $800^{\circ} \mathrm{C}$.

\section{Synthesis of CNT-CDKACT1-Rhoda 6a and CNT-NanoCtrl-Cy5 6b}

\section{Preparation of oxidized MWCNTs 1}

Pristine MWCNTs $(0.5 \mathrm{~g})$ were sonicated in a water bath $(20 \mathrm{~W}, 40 \mathrm{kHz})$ for $24 \mathrm{~h}$ in $75 \mathrm{~mL}$ of sulphuric acid $(98 \%) /$ nitric acid $(65 \%)$ mixture $(3: 1 \mathrm{v} / \mathrm{v})$ at room temperature. The temperature of the water bath was maintained below $35^{\circ} \mathrm{C}$ by adding cold water regularly. The suspension was carefully diluted in cold water $(225 \mathrm{~mL})$ and then filtered using a polytetrafluoroethylene (PTFE) filtration membrane $\left(0.45 \mu \mathrm{m}\right.$, Omnipore ${ }^{\circledR}$ from Millipore). The oxidized MWCNTs (ox-MWCNTs) were re-suspended in water, neutralized with an aqueous $\mathrm{NaOH}$ solution to neutral $\mathrm{pH}$ and filtered again. The $o x$-MWCNTs 1 were dispersed in water and the suspension was dialyzed against deionized water for 2 days and lyophilized.

\section{Preparation of functionalized MWCNTs 3}

A suspension of $o x$-MWCNTs 1 (50 mg) in oxalyl chloride $(8.5 \mathrm{~mL})$ was sonicated in a water bath for $10 \mathrm{~min}$ and then heated at reflux for $24 \mathrm{~h}$. After evaporation under vacuum, the acyl chloride-CNTs were dispersed in a solution of tert-butyl (2-(2-(2aminoethoxy)ethoxy)ethyl)carbamate 2 (450 mg) in dry THF (25 mL) under argon. The mixture was sonicated for $2 \mathrm{~min}$ and heated at reflux for $48 \mathrm{~h}$. The suspension was filtered over a PTFE membrane $(0.1 \mu \mathrm{m})$. The solid recovered on the filter was dispersed in DMF $(100 \mathrm{~mL})$. The suspension was sonicated for $3 \mathrm{~min}$ in a water bath and filtered over a PTFE membrane $\left(0.1 \mu \mathrm{m}\right.$, Omnipore $^{\circledR}$ from Millipore). This sequence was successively repeated with DMF, methanol (twice), and dichloromethane. The resulting solid was dried under vacuum to yield functionalized MWCNTs ( $f$-MWCNTs) 3.

\section{Preparation of functionalized MWCNTs 4}

A suspension of $f$-MWCNTs $3(20 \mathrm{mg})$ in 1,4-dioxane $(10 \mathrm{~mL})$ was sonicated in a water bath for $5 \mathrm{~min}$. A solution of $4 \mathrm{M} \mathrm{HCl}$ in 1,4-dioxane $(10 \mathrm{~mL})$ was added and the suspension was sonicated again for $5 \mathrm{~min}$, stirred for $6 \mathrm{~h}$, and filtered over a PTFE membrane $(0.1 \mu \mathrm{m})$. The solid on the filter was then dispersed in DMF $(40 \mathrm{~mL})$. The suspension was sonicated in a water bath and filtered. This washing sequence was repeated successively with methanol and 
dichloromethane. The solid CNTs was dried under vacuum to give $f$-MWCNTs 4 . The amine loading quantified by Kaiser test was $203 \mu \mathrm{mol} / \mathrm{g}$.

\section{Preparation of functionalized MWCNTs 5}

To a suspension of $f$-MWCNTs $4(12 \mathrm{mg})$ in DCM (12 mL) previously sonicated in a water bath for 5 min were added $N, N$-diisopropylethylamine (DIEA) $(625 \mu \mathrm{L})$ and succinic anhydride $(19 \mathrm{mg})$. The mixture was sonicated again for $5 \mathrm{~min}$ and stirred at room temperature overnight. Succinic anhydride (19 mg) was added again, the suspension was sonicated for $5 \mathrm{~min}$ and stirred for $5 \mathrm{~h}$. The suspension was filtered over a PTFE membrane $(0.1 \mu \mathrm{m})$. The solid was dispersed in DMF (50 mL). The suspension was sonicated for $5 \mathrm{~min}$ and filtered. This washing sequence was successively repeated with methanol and DCM. The solid was dried under vacuum to yield $f$-MWCNTs 5. The amine loading quantified by Kaiser test was $58 \mu \mathrm{mol} / \mathrm{g}$.

\section{Preparation of functionalized MWCNTs $\mathbf{6} \boldsymbol{a}$ and $\mathbf{6} \boldsymbol{b}$}

The protocol is described in the Materials and Methods section in the manuscript.

The peptide loading values for the different CNT conjugates prepared in this study (assessed by TGA) are summarized in the table below expressed as $\mu$ mol or $\mathrm{mg}$ of peptide per gram of CNT conjugate.

\begin{tabular}{|c|c|c|}
\hline CNT-peptide conjugate & Peptide loading $(\boldsymbol{\mu m o l} / \mathbf{g})$ & Peptide loading $(\mathbf{m g} / \mathbf{g})$ \\
\hline CNT-CDKACT1-Rhoda 6a & 9.8 & 60.4 \\
\hline CNT-NanoCtrl-Cy5 6b & 17.6 & 54.4 \\
\hline CNT-CDKACT1-Cy5 13a & 28.9 & 177.1 \\
\hline CNT-NanoCtrl-Dy755 13b & 16.9 & 60.3 \\
\hline $\begin{array}{c}\text { Alexa750-CNT-CDKACT1- } \\
\text { Cy5 20 }\end{array}$ & 18.0 & 110.3 \\
\hline
\end{tabular}

\section{$\underline{2 \text { Synthesis of functionalized MWCNTs 13a and 13b }}$}

\section{Preparation of functionalized MWCNTs 8}

To a dispersion of $o x$-MWCNTs $1(100 \mathrm{mg})$ in anhydrous DMF $(50 \mathrm{~mL})$ previously sonicated in water bath for $10 \mathrm{~min}$ under argon were added paraformaldehyde $(150 \mathrm{mg})$ and a solution of \{2-[2-(2-tert-butoxycarbonylaminoethoxy)ethoxy]ethylamino $\}$ acetic acid 7 (100 mg) in anhydrous DMF $(5 \mathrm{~mL})$. The reaction mixture was heated at $125^{\circ} \mathrm{C}$ under Ar. After $4 \mathrm{~h}$, a 
solution of paraformaldehyde (150 mg) and compound 7 (100 mg) in anhydrous DMF (5 mL) was added. The additions were repeated another 2 times at minimum intervals of $4 \mathrm{~h}$ during 2 days. After the reaction mixture was allowed to cool down to room temperature, the suspension was filtered over a PTFE membrane $(0.45 \mu \mathrm{m})$. The solid on the filter was dispersed in DMF (200 mL) and the suspension was filtered again. The washing sequence was successively repeated twice with methanol and once with DCM. The solid was dried under vacuum to give $f$-MWCNTs 8. An aliquot of $f$-MWCNTs 8 was used for cleavage of the Boc protecting group using $\mathrm{HCl}$ in 1,4-dioxane following the protocol reported for the preparation of $f$-MWCNTs 4. The Kaiser test ( $93 \mu \mathrm{mol} / \mathrm{g})$ confirmed the presence of ammonium groups.

\section{Preparation of functionalized MWCNTs 10}

To a suspension of $f$-MWCNTs $8(50 \mathrm{mg})$ in anhydrous DMF $(50 \mathrm{~mL})$ were added EDC.HCl (300 mg), DIEA (407 $\mu \mathrm{L})$, and 2-(2-(2-(2-aminoethoxy)ethoxy)ethyl)isoindoline-1,3-dione 9 (300 mg) under argon. The reaction mixture was stirred for $24 \mathrm{~h}$ and then filtered over a PTFE membrane $(0.1 \mu \mathrm{m})$. The solid recovered on the filter was dispersed in DMF $(75 \mathrm{~mL})$. The suspension was sonicated for $5 \mathrm{~min}$ in a water bath and filtered. This sequence was repeated successively with DMF, methanol, and dichloromethane. The solid was dispersed in MilliQ water, the suspension was dialyzed against deionized water for 2 days and lyophilized to yield $f$-MWCNTs $\mathbf{1 0}$.

\section{Preparation of functionalized MWCNTs 11}

The $f$-MWCNTs $10(50 \mathrm{mg})$ were dispersed in ethanol $(20 \mathrm{~mL})$ by sonicating in a water bath for $10 \mathrm{~min}$. Hydrazine monohydrate $98 \%(200 \mu \mathrm{L})$ was added and the suspension was stirred for $6 \mathrm{~h}$. Ethanol $(100 \mathrm{~mL})$ was added and the suspension was filtered over a PTFE membrane $(0.45 \mu \mathrm{m})$. The solid on the filter was dispersed in DMF and the suspension was filtered again. The washing sequence was successively repeated twice with methanol and once with DCM. The solid was dried under vacuum to give $f$-MWCNTs 11. The amine loading estimated by Kaiser test was $87 \mu \mathrm{mol} / \mathrm{g}$.

\section{Preparation of functionalized MWCNTs 12}

To a suspension of $f$-MWCNTs $11(50 \mathrm{mg})$ in DCM $(50 \mathrm{~mL})$ previously sonicated in a water bath for $5 \mathrm{~min}$ were added DIEA $(2.5 \mathrm{~mL})$ and succinic anhydride $(76 \mathrm{mg})$. The mixture was sonicated again for $5 \mathrm{~min}$ and stirred at room temperature overnight. Succinic anhydride (76 $\mathrm{mg}$ ) was added again, the suspension was sonicated for $5 \mathrm{~min}$ and stirred for $5 \mathrm{~h}$. The suspension 
was filtered over a PTFE membrane $(0.1 \mu \mathrm{m})$. The solid was dispersed in DMF (200 mL). The suspension was sonicated for $5 \mathrm{~min}$ and filtered. This washing sequence was successively repeated with methanol and DCM. The solid was dried under vacuum to yield $f$-MWCNTs 12 . The amine loading quantified by Kaiser test was $20 \mu \mathrm{mol} / \mathrm{g}$.

\section{Preparation of functionalized MWCNTs $13 a$ and $\mathbf{1 3 b}$}

The protocol is described in the Materials and Methods section in the manuscript.

\section{Synthesis of alkyne-PEG-Alexa750 linker 16}

Synthesis of tert-butyl (37-oxo-3,6,9,12,15,18,21,24,27,30,33-undecaoxa-36-azadotetracont41-yn-1-yl)carbamate (alkyne-PEG-NHBoc linker) 14

To a solution of 5-hexynoic acid $\left(34.8 \mathrm{mg}, 0.31 \mathrm{mmol}, 1\right.$ eq.) in $\mathrm{CHCl}_{3}(3 \mathrm{~mL})$ under argon at $0^{\circ} \mathrm{C}$ were added DIEA (70 $\mu \mathrm{L}, 1.3$ eq.) and after $5 \mathrm{~min} \mathrm{EDC} . \mathrm{HCl}$ (71.3 mg, 1.2 eq.). After $15 \mathrm{~min}$, a precooled solution of hydroxybenzotriazole (HOBt) (49.8 mg, 1.05 eq.) in DMF $(250 \mu \mathrm{L})$ was added. The reaction mixture was further stirred at $0^{\circ} \mathrm{C}$ for $30 \mathrm{~min}$. $O-(2-$ aminoethyl)-O'-[2-(Boc-amino)ethyl]decaethylene glycol (200 mg, 1 eq.) was added. The pH of the reaction mixture was adjusted to 8 and stirred overnight under argon at room temperature. The solvent was removed under reduced pressure and the crude was purified by flash column chromatography using the solvent gradient $\mathrm{DCM} / \mathrm{MeOH}$ (97:3 to 92:8) to give $\mathbf{1 4}$ as colourless thick liquid (156 mg, yield: 68\%). ${ }^{1} \mathrm{H}$ NMR (400 MHz, $\left.\mathrm{CDCl}_{3}\right) \delta(\mathrm{ppm}): 6.20$ (br s, 1H), 5.01 (br s, 1H), 3.60 (s, $40 \mathrm{H}), 3.48-3.53(\mathrm{~m}, 4 \mathrm{H}), 3.41$ (t, $J=8.8 \mathrm{~Hz}, 2 \mathrm{H}), 3.20-3.30$ (m, 2H), 2.28 $(\mathrm{t}, J=8 \mathrm{~Hz}, 2 \mathrm{H}), 2.21(\mathrm{t}, J=7 \mathrm{~Hz}, 2 \mathrm{H}), 1.95(\mathrm{~s}, 1 \mathrm{H}), 1.75-1.90(\mathrm{~m}, 2 \mathrm{H}), 1.40$ (s, 9H). ESI mass spectrometry: $m / z=739.07[\mathrm{M}+\mathrm{H}]^{+}$.

Synthesis of 37-oxo-3,6,9,12,15,18,21,24,27,30,33-undecaoxa-36-azadotetracont-41-yn-1aminium chloride (alkyne-PEG-ammonium linker) 15

A solution of alkyne-PEG-NH-Boc 14 (40 mg, $54 \mu \mathrm{mol})$ in $4 \mathrm{M} \mathrm{HCl}$ in 1,4-dioxane $(10 \mathrm{~mL})$ was stirred for $5 \mathrm{~h}$. The solvent was evaporated in vacuum to yield alkyne-PEG-ammonium 15 (34 mg, 99\% yield). ${ }^{1} \mathrm{H}$ NMR (400 MHz, CDCl3) $\delta$ (ppm): 7.12 (br s, 2H), 6.92 (br s, 1H), 3.78-3.80 (m, 2H), 3.56-3.70 (m, 42H), 3.44-3.47 (m, 2H), 3.14-3.18 (m, 2H), 2.41 (t, J=7.4 $\mathrm{Hz}, 2 \mathrm{H}), 2.23(\mathrm{t}, \mathrm{J}=6.8 \mathrm{~Hz}, 2 \mathrm{H}), 1.98(\mathrm{~s}, 1 \mathrm{H}), 1.80-1.97(\mathrm{~m}, 2 \mathrm{H})$. ESI mass spectrometry: $m / z=$ 639.58 [M]. 
Synthesis of Alexa750-functionalized N-(1-oxo-5,8,11,14,17,20,23,26,29,32,35-undecaoxa-2azaheptatriacontan-37-yl)hex-5-ynamide (alkyne-PEG-Alexa750 linker) 16

To a solution of Alexa Fluor ${ }^{\circledR} 750$ carboxylic acid, tris(triethylammonium) salt (5 mg, $4.2 \mu \mathrm{mol}$, 1 eq.) in anhydrous DMF $(2 \mathrm{~mL})$ at $0^{\circ} \mathrm{C}$ were added 1-[bis(dimethylamino)methylene]-1H1,2,3-triazolo[4,5-b]pyridinium 3-oxid hexafluorophosphate (HATU) (3.16 mg, 2 eq.) and DIEA ( $2.2 \mu \mathrm{L}, 3$ eq.). The reaction mixture was stirred for 15 min maintaining the temperature at $0^{\circ} \mathrm{C}$. A solution of alkyne-PEG-ammonium linker $15(3.2 \mathrm{mg}, 1.2 \mathrm{eq})$ in anhydrous DMF $(1 \mathrm{~mL})$ neutralized to $\mathrm{pH} \sim 8$ by adding DIEA $(0.9 \mu \mathrm{L}, 1.2 \mathrm{eq})$ was added dropwise. After $5 \mathrm{~min}$, the $\mathrm{pH}$ of the reaction mixture was adjusted to 7-8 and the solution was stirred overnight in cold conditions $\left(4^{\circ} \mathrm{C}\right)$ and then at room temperature for $2 \mathrm{~h}$. The reaction mixture was diluted in water and lyophilized to remove DMF. The crude was purified by preparative HPLC to obtain alkyne-PEG-Alexa750 linker 16, (4 mg, 64\% yield). ESI mass spectrometry: $\mathrm{m} / \mathrm{z}=1505.85$ $[\mathrm{M}+\mathrm{H}]^{+}$.

\section{Synthesis of functionalized MWCNTs 20}

\section{Preparation of functionalized MWCNTs 17}

The protocol used for Boc deprotection to prepare $f$-MWCNTs 4 was followed to prepare $f$-MWCNTs 17 starting from $f$-MWCNTs $12(65 \mathrm{mg})$ suspended in 1,4-dioxane (30 mL) and 4 $\mathrm{M} \mathrm{HCl}$ in 1,4-dioxane $(30 \mathrm{~mL})$. The amine loading estimated by Kaiser test was $93 \mu \mathrm{mol} / \mathrm{g}$.

\section{Preparation of functionalized MWCNTs 18}

To a solution of 5-azidopentanoic acid (1.67 mg, $11.7 \mu \mathrm{mol}, 1$ eq.) in anhydrous DMF (5 mL) at $0^{\circ} \mathrm{C}$ under argon were added $\mathrm{EDC} . \mathrm{HCl}(3.36 \mathrm{mg}, 1.5$ eq.) and $\mathrm{HOBt}(1.97 \mathrm{mg}, 1.1$ eq.). After $30 \mathrm{~min}$ stirring at $0^{\circ} \mathrm{C}, f$-MWCNTs $17(35 \mathrm{mg})$ and DIEA $(20 \mu \mathrm{L})$ were added. The suspension was sonicated for $10 \mathrm{~min}$ and stirred at room temperature for 1 day. The reaction mixture was filtered over a PTFE membrane $(0.1 \mu \mathrm{m})$. The solid recovered on the filter was dispersed in DMF (70 mL). The suspension was sonicated for $5 \mathrm{~min}$ in a water bath and filtered. This sequence was repeated successively with DMF, methanol, and dichloromethane. The solid was dried under vacuum to give $f$-MWCNTs $\mathbf{1 8}$. The amine loading estimated by Kaiser test was $31 \mu \mathrm{mol} / \mathrm{g}$.

\section{Preparation of functionalized MWCNTs 19}

To a suspension of $f$-MWCNTs $18(30 \mathrm{mg})$ in water/ $\mathrm{CH}_{3} \mathrm{OH}(1.5 / 0.5 \mathrm{~mL})$ sonicated in a water bath for 5 min was added a solution of alkyne-PEG-Alexa750 linker 17 (3.36 mg, $2.2 \mu \mathrm{mol}, 1.2$ 
eq.) in water $(2 \mathrm{~mL})$. A solution of a catalytic amount of copper(II) sulphate pentahydrate and sodium ascorbate in water $(0.5 \mathrm{~mL})$ was added. The mixture was sonicated in a water bath for 5 min and stirred for 2 days in the dark. The suspension was filtered over a PTFE $(0.1 \mu \mathrm{m})$ membrane. The solid recovered on the filter was dispersed in DMF (50 mL). The suspension was sonicated for $10 \mathrm{~min}$ in a water bath and filtered over a PTFE $(0.1 \mu \mathrm{m})$ membrane. This sequence was successively repeated with DMF, twice with methanol, and once with dichloromethane. The solid was dispersed in MilliQ water and the suspension was dialyzed against MilliQ water for 2 days. Lyophilization allowed obtaining Alexa750-functionalized MWCNTs 19. The degree of Alexa750 conjugation estimated by TGA was $16.3 \mu$ mol per $g$ of CNTs (Figure S9C). 


\section{Supplementary Figures}

A

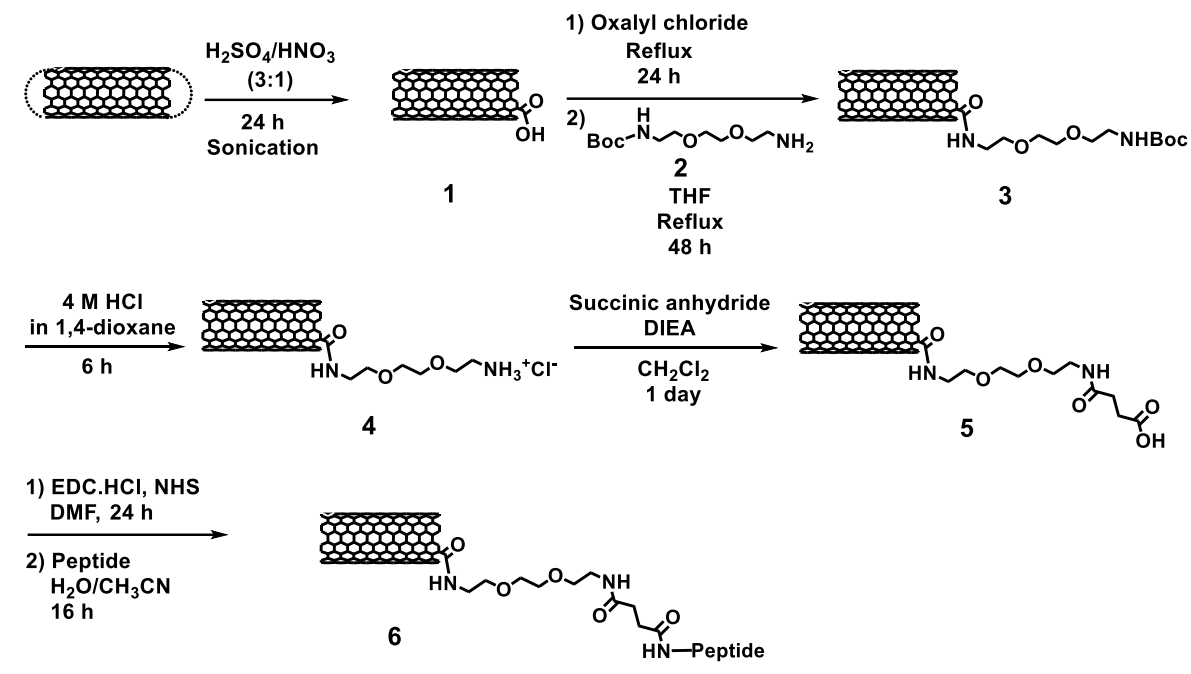

B

a)

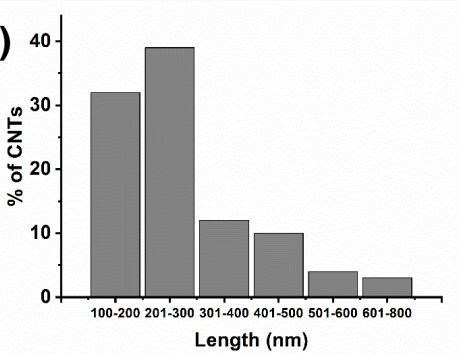

e)

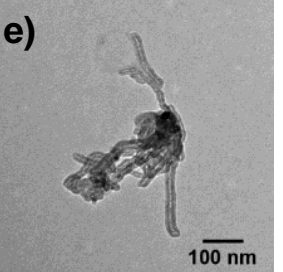

b)

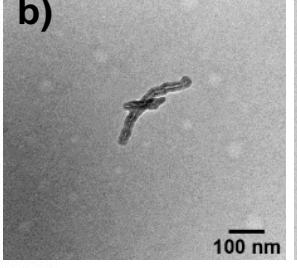

c)
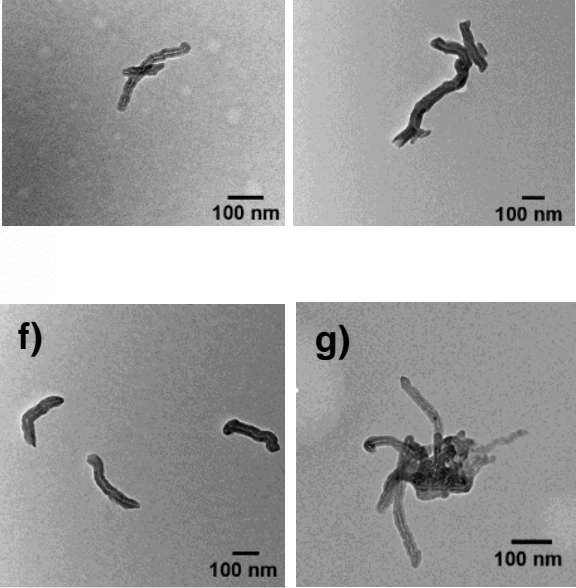

d)

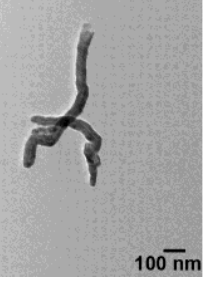

C

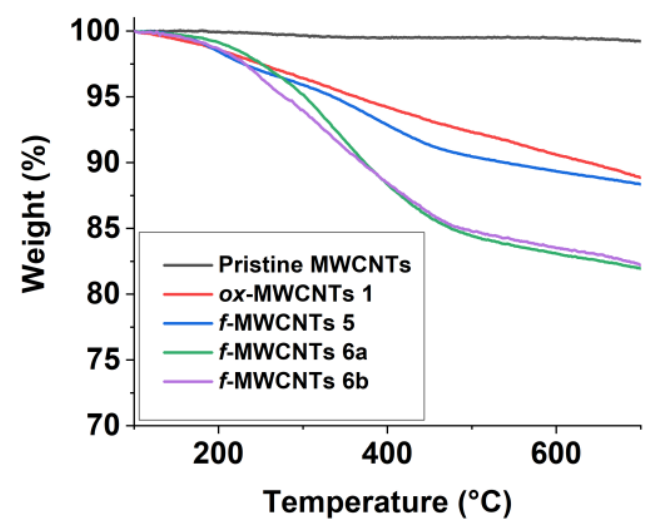

Figure S1. (A) Synthesis of MWCNT-CDKACT1-Rhoda 6a and MWCNT-NanoCtrl-Cy5 6b. (B) Length distribution of the oxidized MWCNTs 1 ( $\mathrm{n}=91$; average length: $270 \mathrm{~nm}$ ) (a) and 
transmission electron microscopy (TEM) images of (b) the oxidized MWCNTs $\mathbf{1}$ and the functionalized MWCNTs 6a (c), 6b (d), 13a (e), 13b (f), and 20 (g). (C) Thermogravimetric analysis (TGA) of pristine MWCNTs, oxidized MWCNTs 1, and functionalized MWCNTs ( $f$-MWCNTs) $\mathbf{5}, \mathbf{6 a}$, and $\mathbf{6 b}$ performed under $\mathrm{N}_{2}$.

$\mathbf{A}$
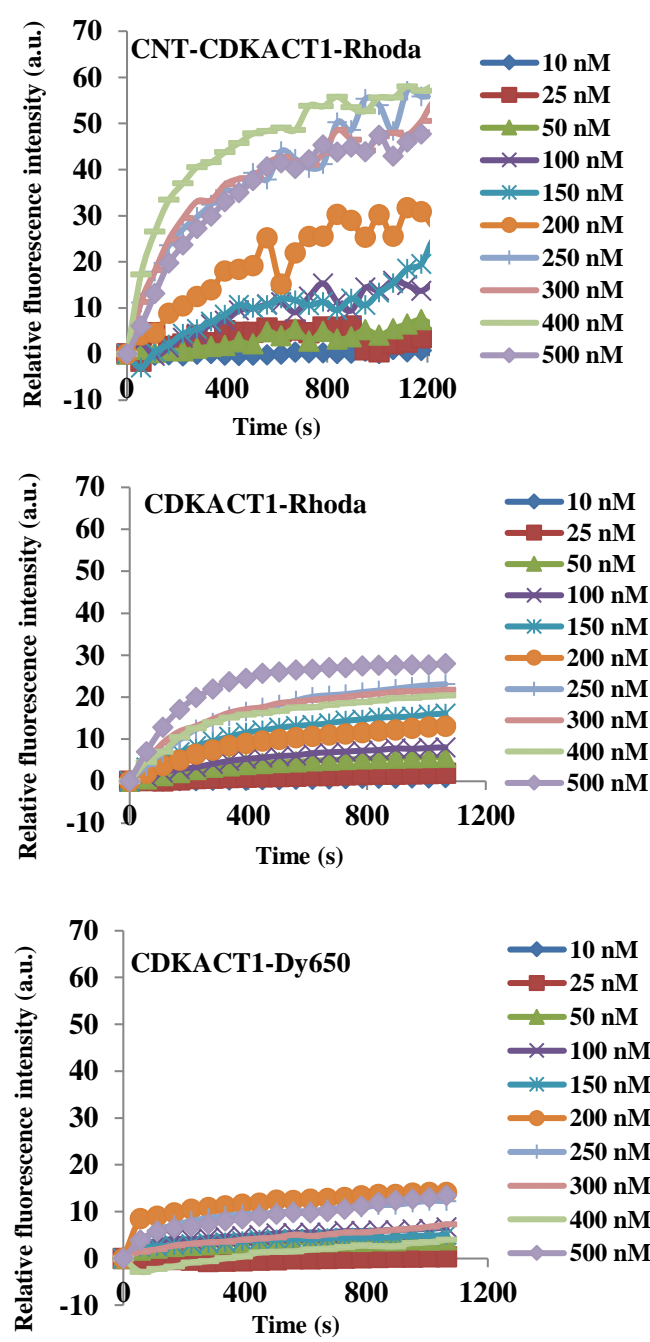

\section{B}
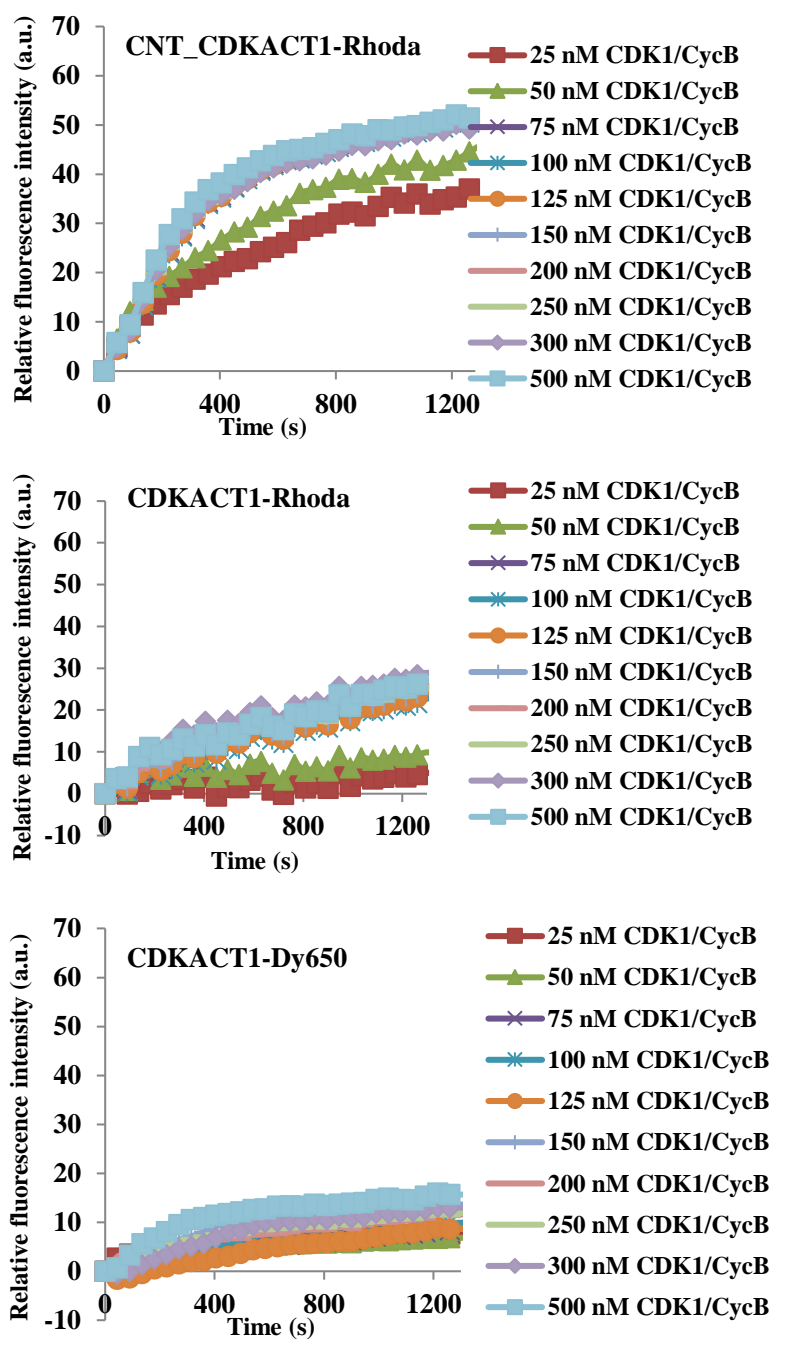

Figure S2. Dose-dependent response of CNT-CDKACT1-Rhoda biosensor conjugates, of CDKACT1-Rhoda peptide biosensor and of CDKACT1-Dylight650 to CDK1/Cyclin B1: (A) fixed concentration of recombinant kinase ( $75 \mathrm{nM}$ ) vs different concentrations of biosensor (0-500 $\mathrm{nM}$ of peptide corresponding to $0-51 \mu \mathrm{g} / \mathrm{mL}$ of CNTs) (left panels), (B) fixed concentration of biosensor $(250 \mathrm{nM})$ vs different concentrations of recombinant kinase (right panels). 

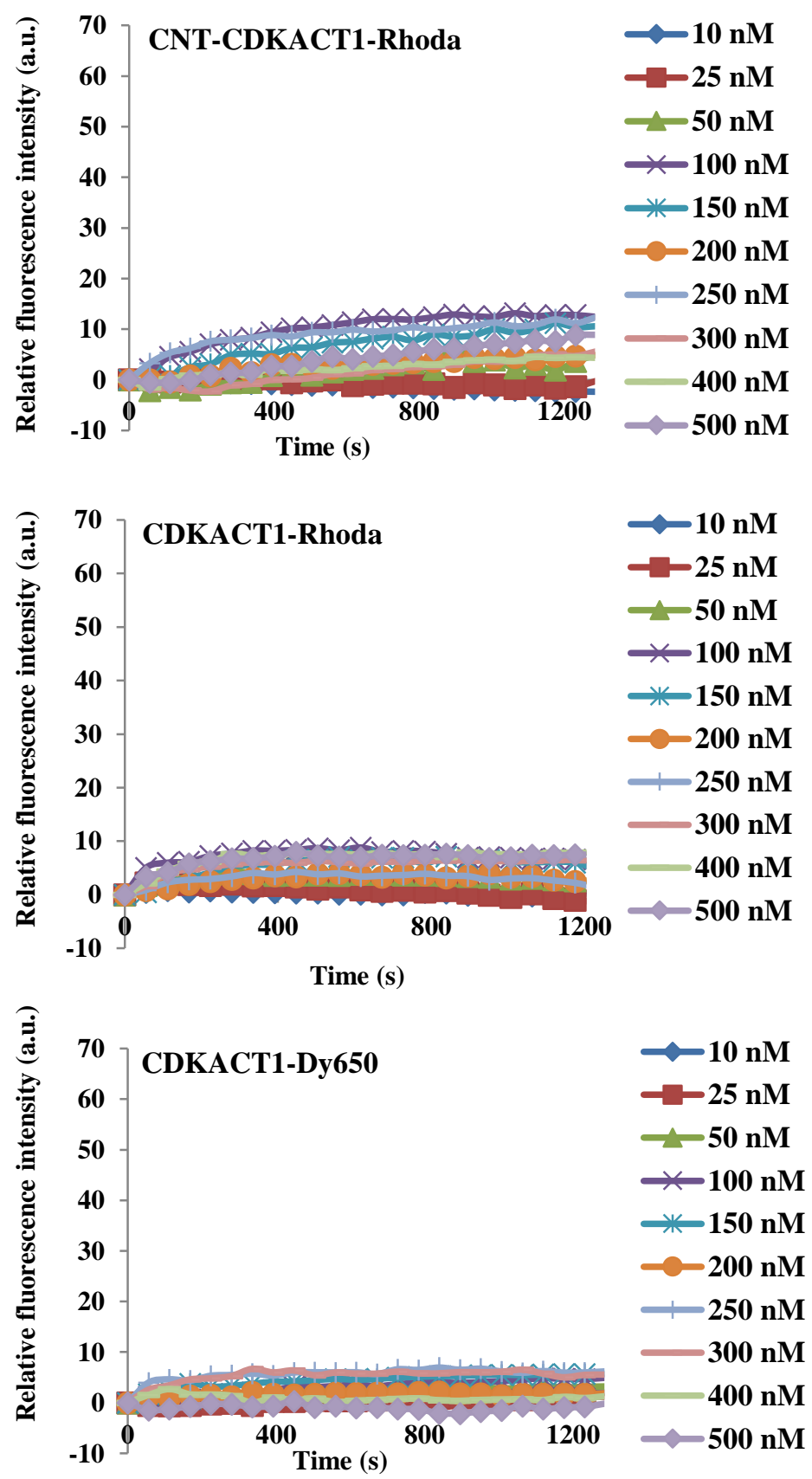

Figure S3. Dose-dependent response of CNT-CDKACT1-Rhoda biosensor conjugates, of CDKACT1-Rhoda peptide biosensor and of CDKACT1-Dy650 to CDK2/Cyclin A: fixed concentration of recombinant kinase $(75 \mathrm{nM})$ vs different concentrations of biosensor. 
A
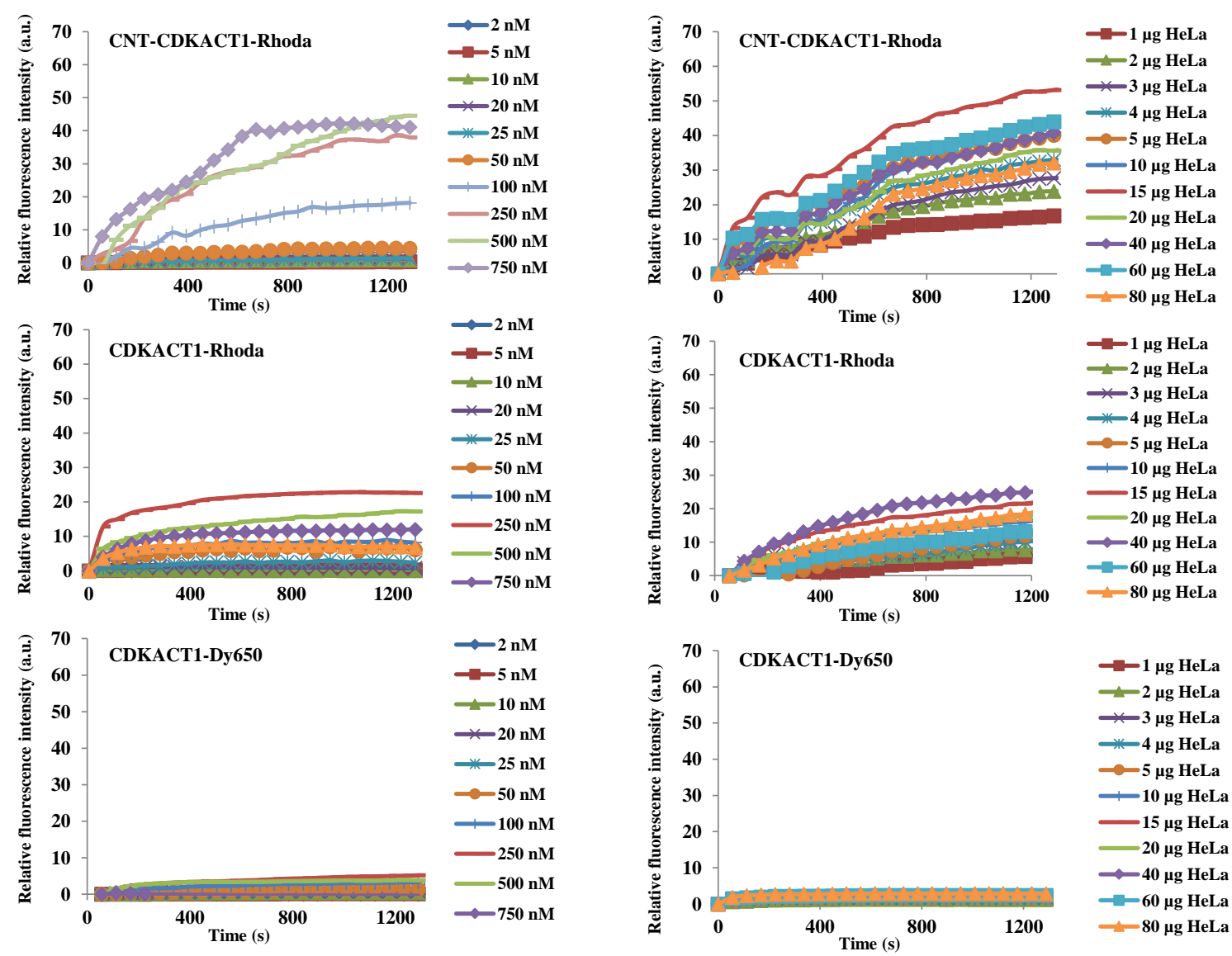

B
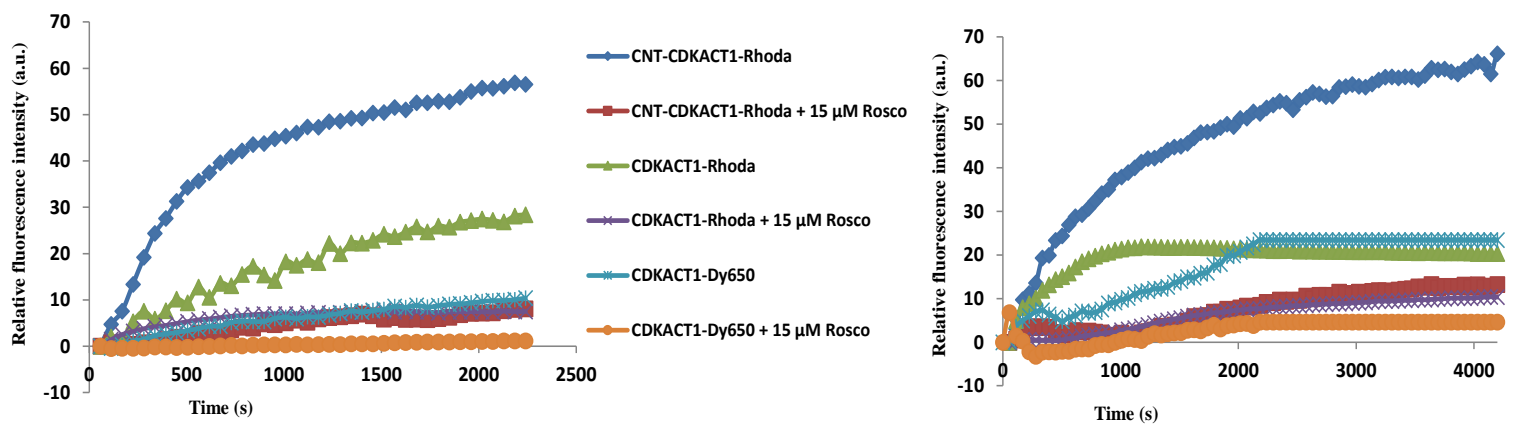

Figure S4. (A) Dose-dependent response of CNT-CDKACT1-Rhoda biosensor conjugates, of CDKACT1-Rhoda peptide biosensor and of CDKACT1-Dy650 to cell extracts: (left panels) fixed concentration of $40 \mu \mathrm{g}$ HeLa cell extract incubated with different concentrations of biosensor, (right panels) fixed concentration of $250 \mathrm{nM}$ biosensor incubated with different concentrations of HeLa cell extracts. (B) Response of CNT-CDKACT1-Rhoda biosensor conjugates, of CDKACT1-Rhoda peptide and of CDKACT1-Dy650 to inhibition of kinase activity: (left panel) $75 \mathrm{nM}$ recombinant CDK1/Cyclin B1 incubated with $250 \mathrm{nM}$ biosensor in 
the presence or absence of $15 \mu \mathrm{M}$ Roscovitine, (right panel) $40 \mu \mathrm{g}$ HeLa cell extracts incubated with $250 \mathrm{nM}$ biosensor in the presence or absence of $15 \mu \mathrm{M}$ Roscovitine. 
A

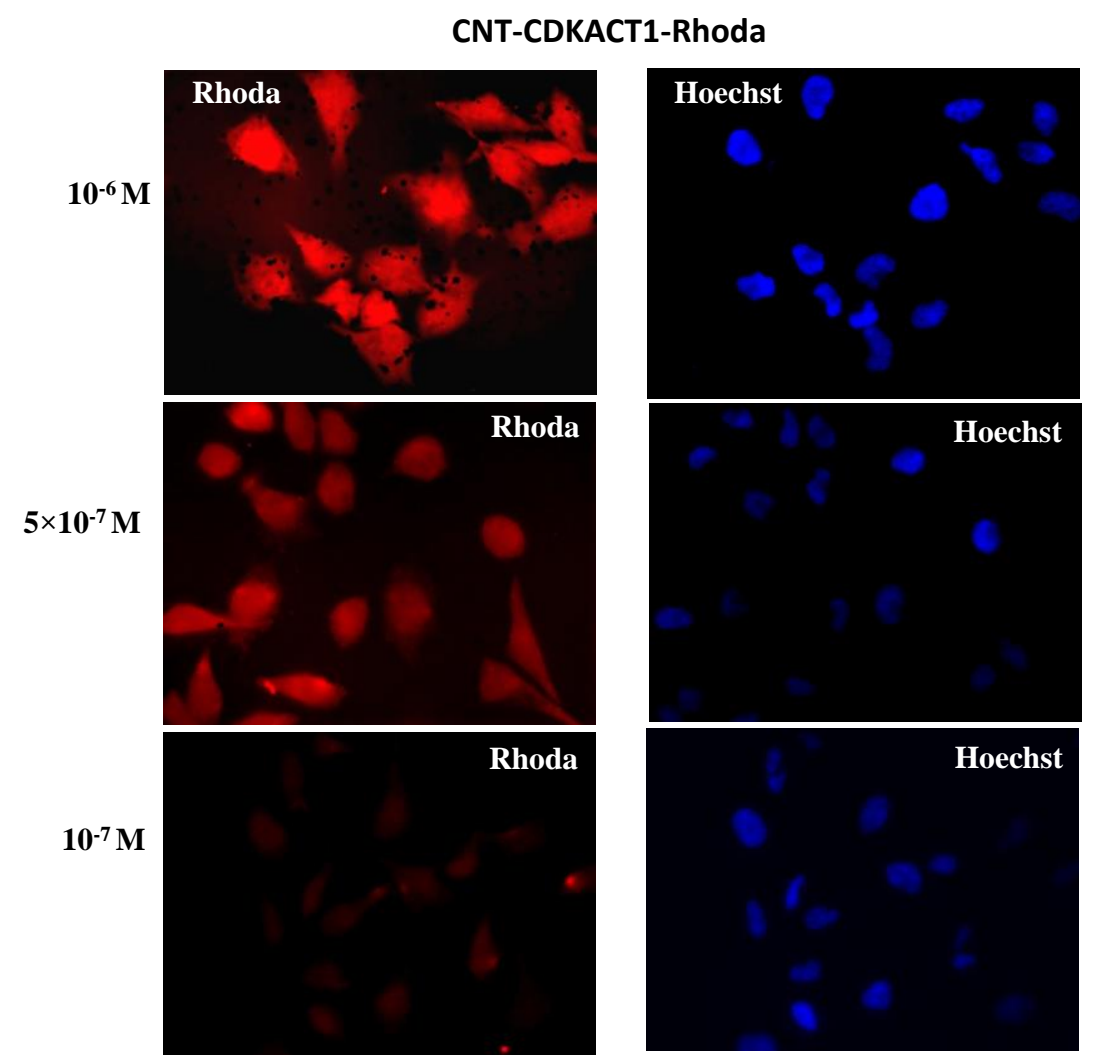

B

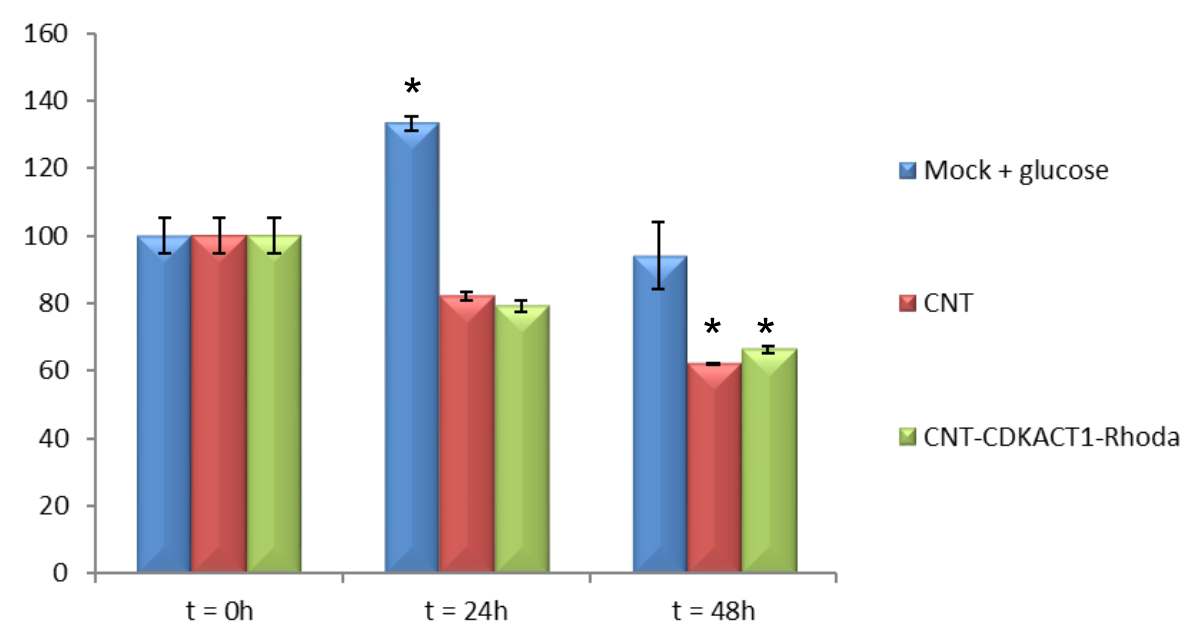

Figure S5. (A) Cellular internalization of different concentrations of CNT-CDKACT1-Rhoda into HeLa cells (0.1-1 $\mu \mathrm{M}$ peptide corresponding to 10-102 $\mu \mathrm{g} / \mathrm{mL}$ CNTs). (B) Toxicity studies: HeLa cells were either mock-treated (PBS $+5 \%$ glucose) or treated with $0.5 \mu \mathrm{M} f$-MWCNTs 5 (corresponding to $50 \mu \mathrm{g} / \mathrm{mL}$ CNTs) or CNT-CDKACT1-Rhoda conjugate and cellular viability was measured by crystal violet staining after $24 \mathrm{~h}$ and $48 \mathrm{~h}$, respectively. 
A

a)

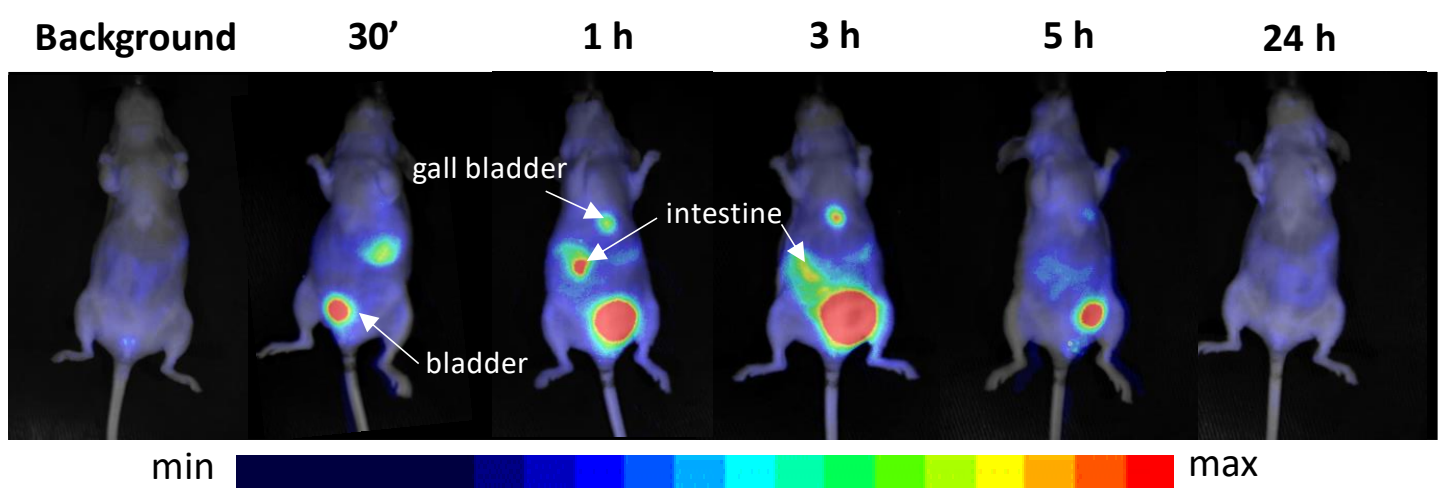

b)

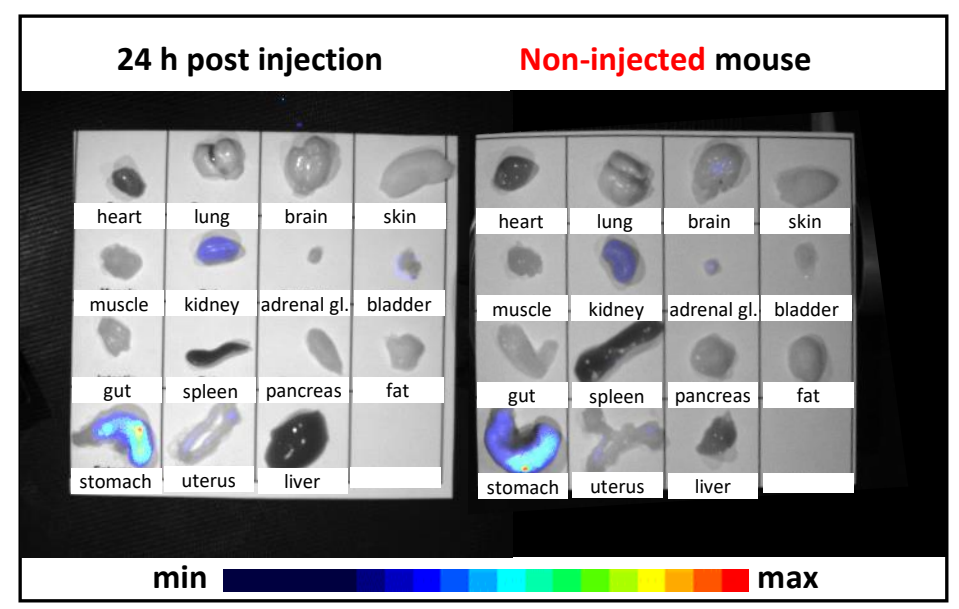

B

a)

b)
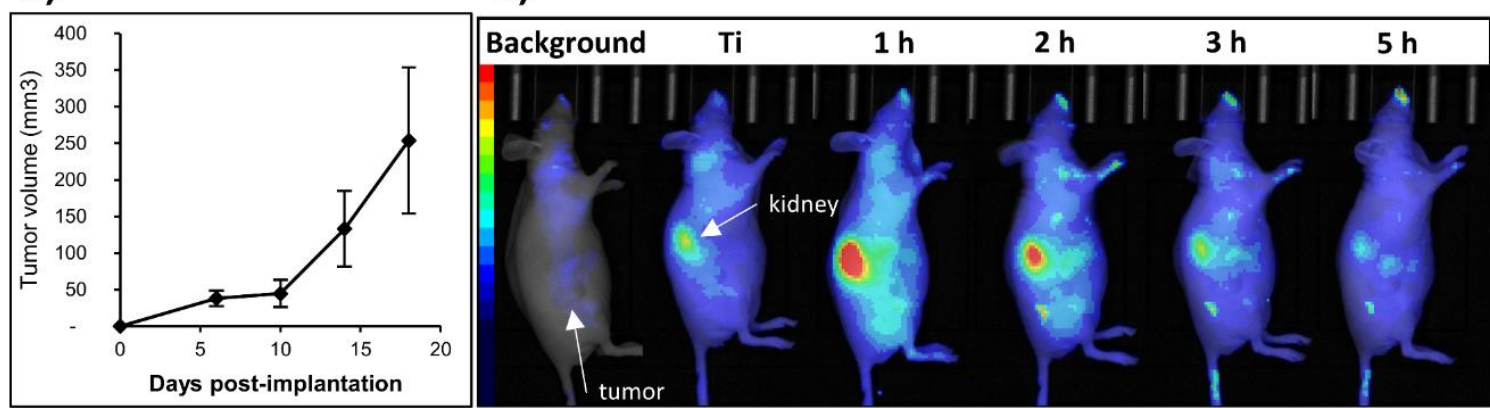

c)

d)
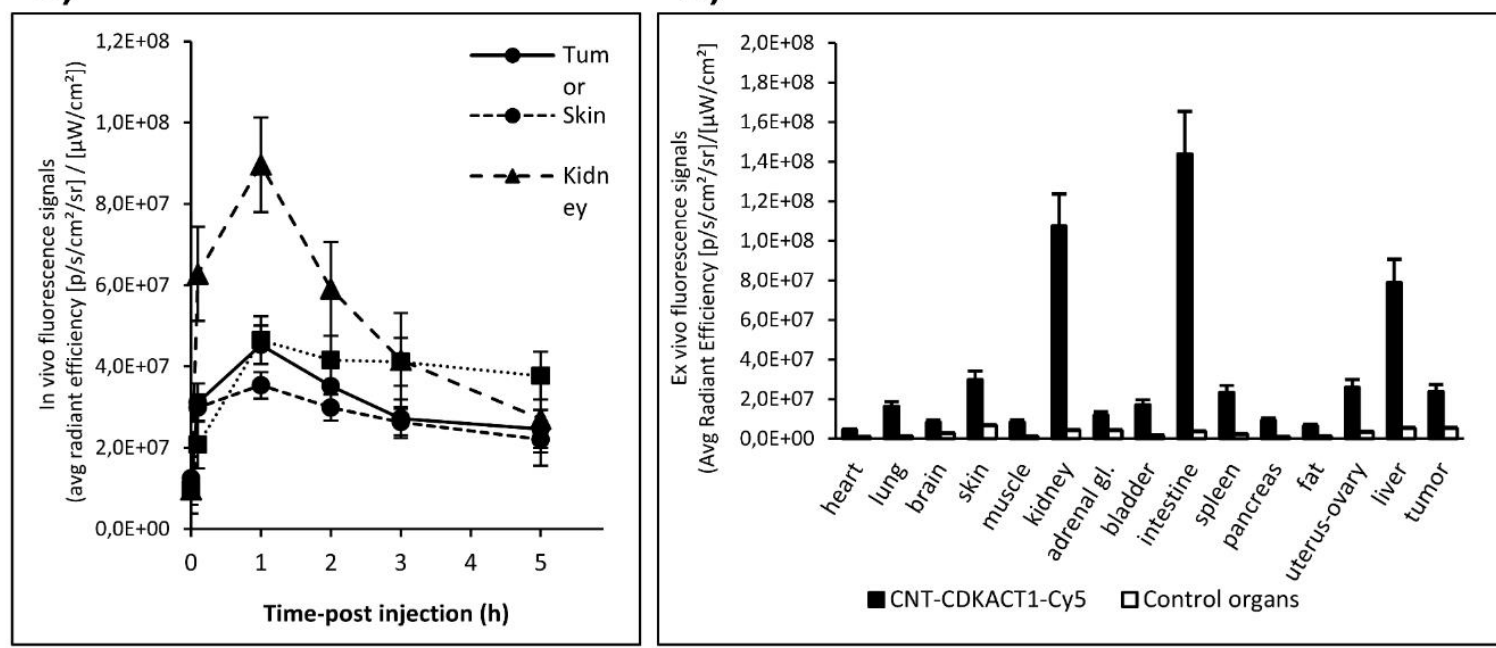
Figure S6. (A) (a) In vivo biodistribution and pharmacokinetics of CNT-control peptide in mice. In vivo fluorescence imaging of CNT-NanoCtrl-Cy5 (excitation: $640 \pm 15 \mathrm{~nm}$; recording: $700 \pm 10 \mathrm{~nm})$ at various time points after intravenous injection in healthy mice (200 $\mu \mathrm{L}$ at $6 \mu \mathrm{M}$ determined by quantifying probe fluorescence, corresponding to $68 \mu \mathrm{g}$ functionalized CNTs). (b) Ex vivo fluorescence images of CNT-NanoCtrl-Cy5 in isolated organs $24 \mathrm{~h}$ after intravenous injection in healthy mice compared to a non-injected mouse (tissue autofluorescence). (B) Evaluation of CNT-CDKACT1-Cy5 tumor uptake in mice. (a) Tumor growth of A375 melanoma xenografts: A375 cells $\left(3 \times 10^{6}, 200 \mu \mathrm{L}\right.$ in PBS) were implanted subcutaneously in the right flank and tumor volume was monitored by caliper measurement. (b) In vivo fluorescence imaging of CNT-CDKACT1-Cy5 (excitation: $640 \pm 15 \mathrm{~nm}$; recording: $700 \pm 10 \mathrm{~nm}$ ) at various time points after intravenous injection $(200 \mu \mathrm{L}$ at $10 \mu \mathrm{M}$, determined by quantifying peptide fluorescence, corresponding to $114 \mu \mathrm{g}$ of functionalized CNTs) in subcutaneous melanoma tumor (A375)-bearing mice. (c) Kinetics of fluorescence signals from various tissues in vivo after intravenous injection of CNT-CDKACT1-Cy5 in melanoma tumor-bearing mice. (d) Ex vivo fluorescence signals of CNT-CDKACT1-Cy5 in isolated organs $5 \mathrm{~h}$ after intravenous injection in melanoma tumor-bearing mice. 
A
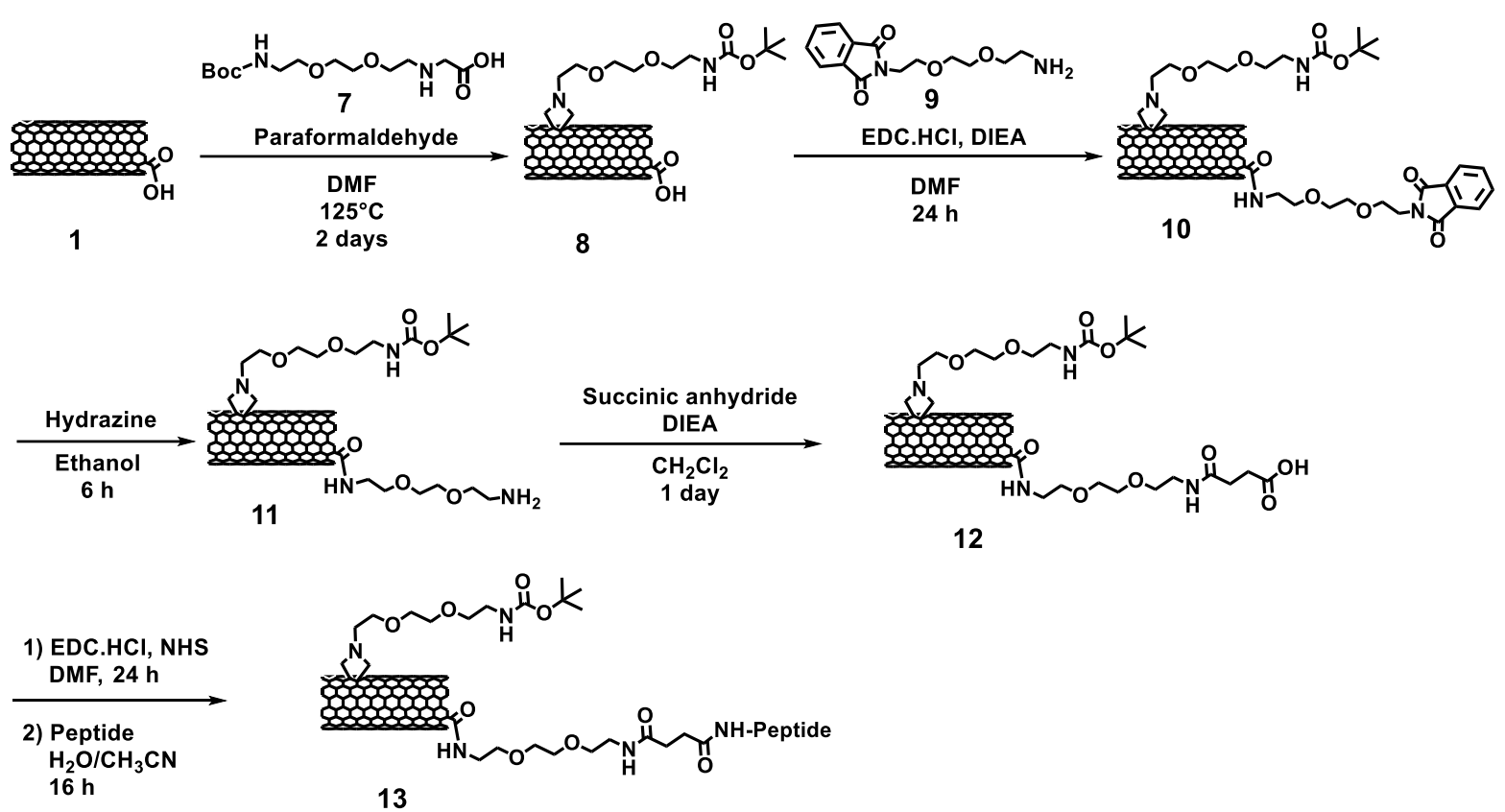

B

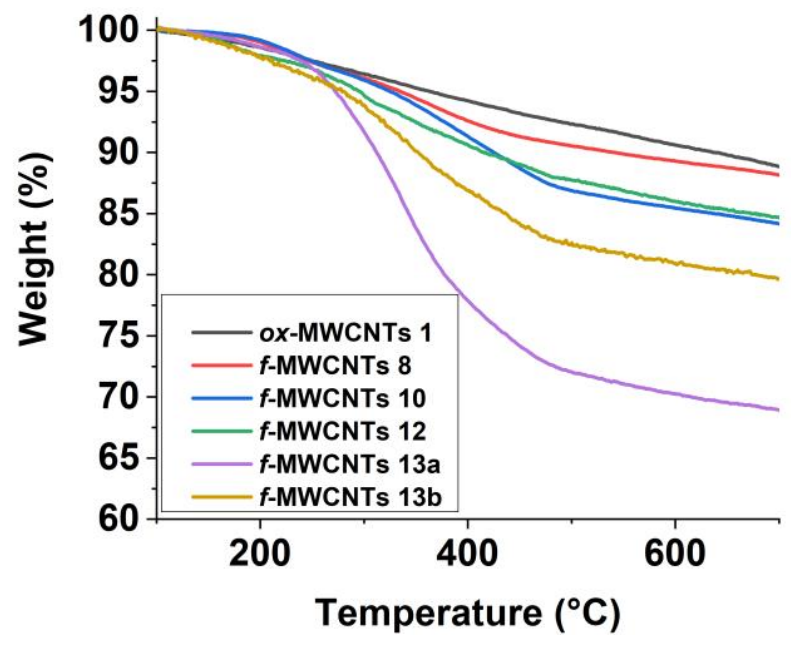

Figure S7. (A) Synthesis of functionalized MWCNTs 13a and 13b. (B) TGA of $o x$-MWCNTs 1 and $f$-MWCNTs $8,10,12,13 \mathbf{a}$, and $\mathbf{1 3 b}$ performed under $\mathrm{N}_{2}$. 


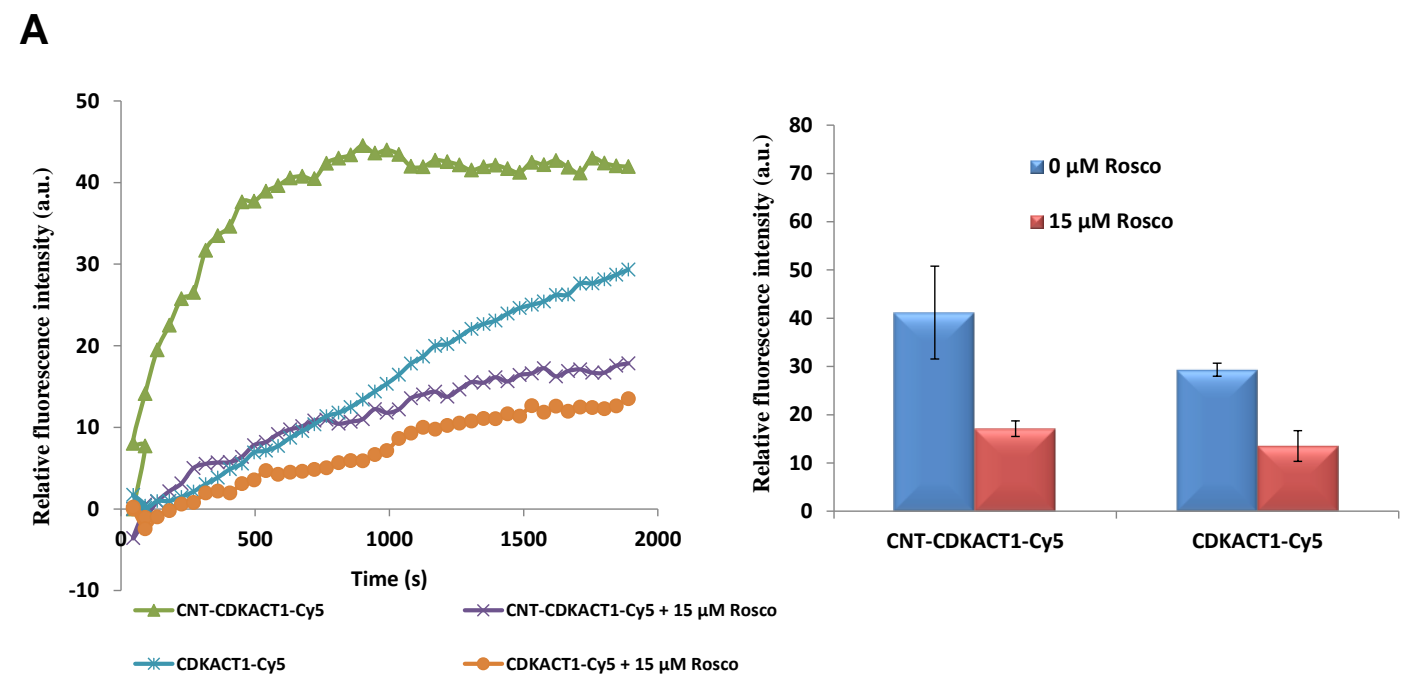

B
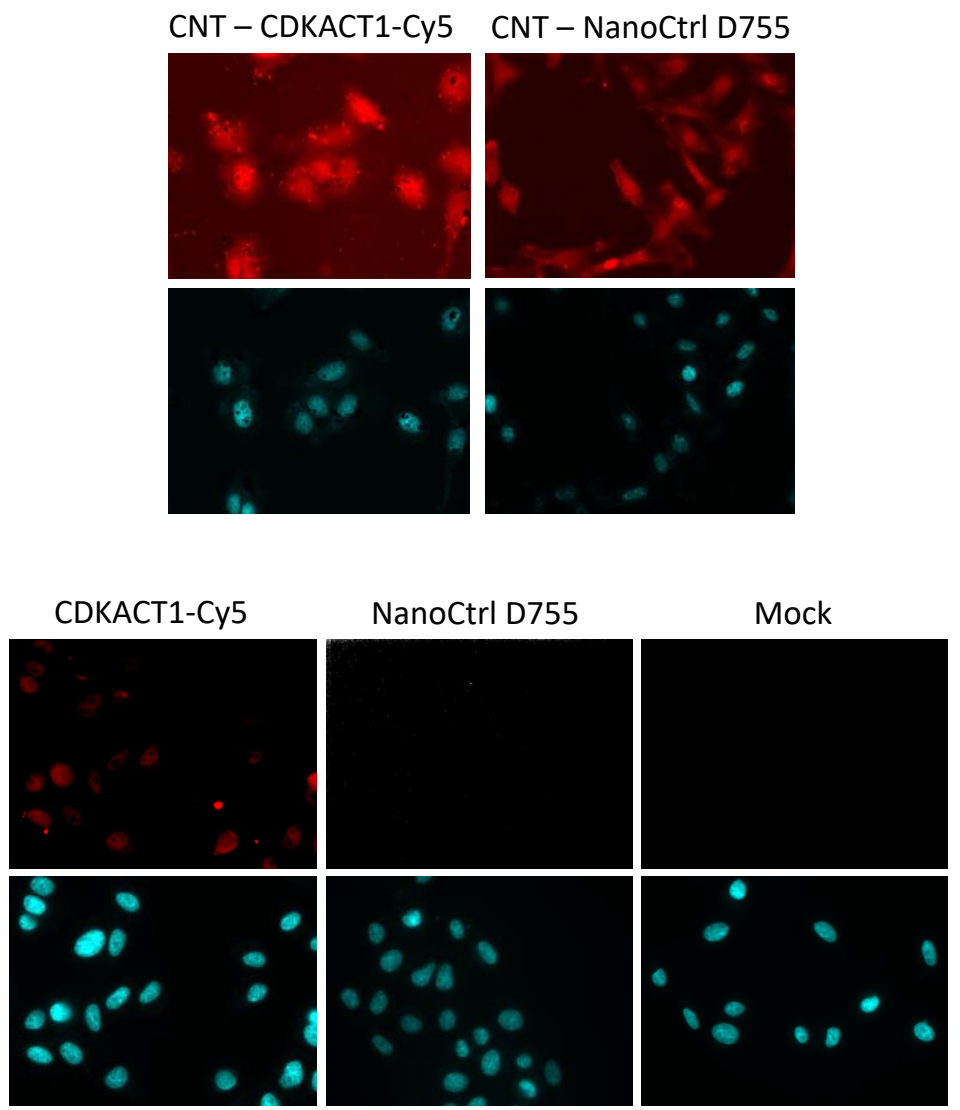

Figure S8. (A) Response of CNT-CDKACT1-Cy5 and CDKACT1-Cy5 peptide. Peptide at 250 $\mathrm{nM}$ concentration, alone and conjugated to CNTs (corresponding to $9 \mu \mathrm{g} / \mathrm{mL}$ of CNTs) incubated with $40 \mu \mathrm{g}$ HeLa cell extracts in the presence or absence of $15 \mu \mathrm{M}$ Roscovitine. Upper panel shows fluorescence emission over time. Bottom panels shows the final response at 1800s. (B) Imaging CNT-CDKACT1-Cy5 and CNT-NanoCtrl-Dy755 in HeLa cells $(0.5 \mu \mathrm{M}$ peptide corresponding to $50 \mu \mathrm{g} / \mathrm{mL} \mathrm{CNTs).}$ 
A

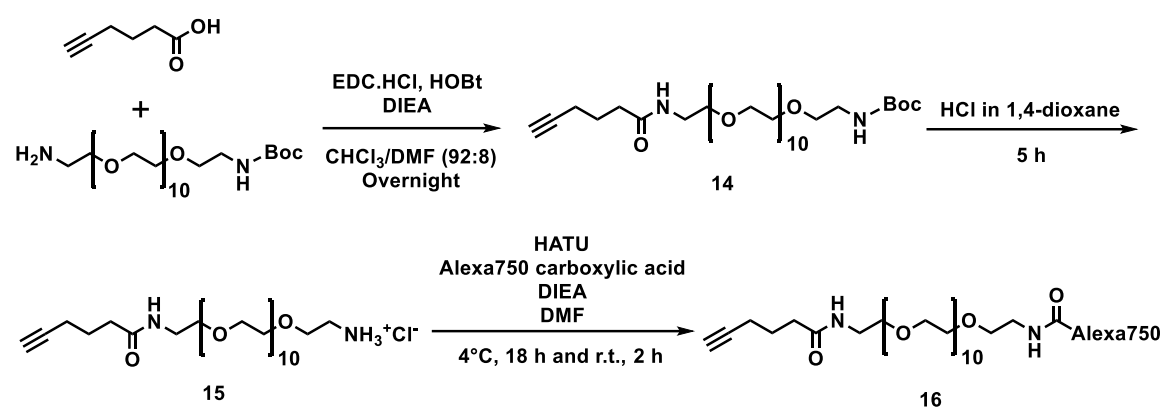

B
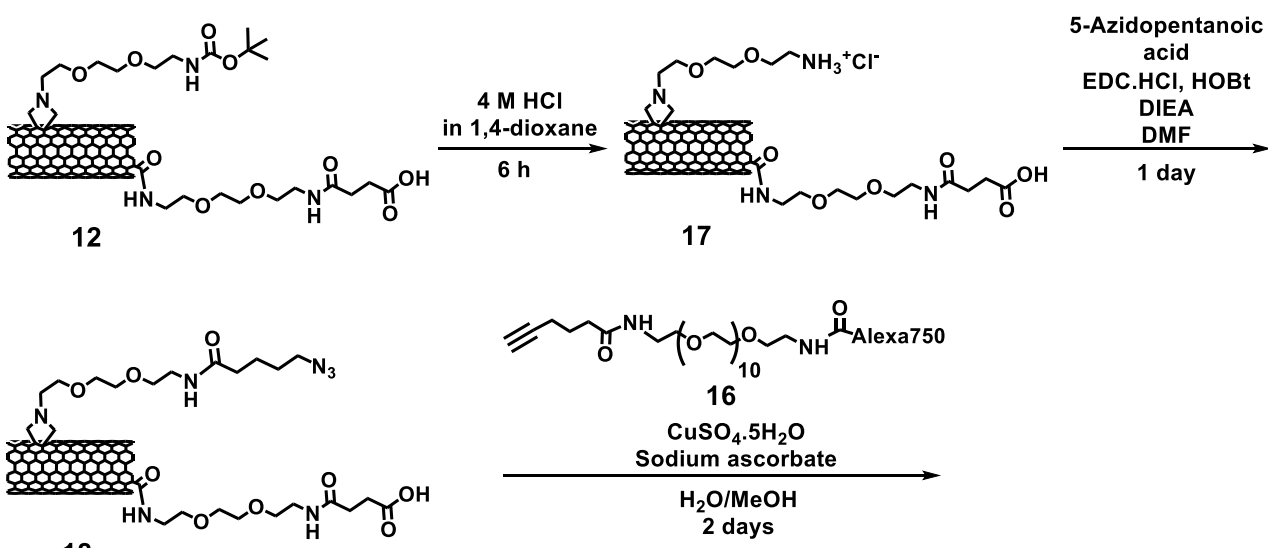

18
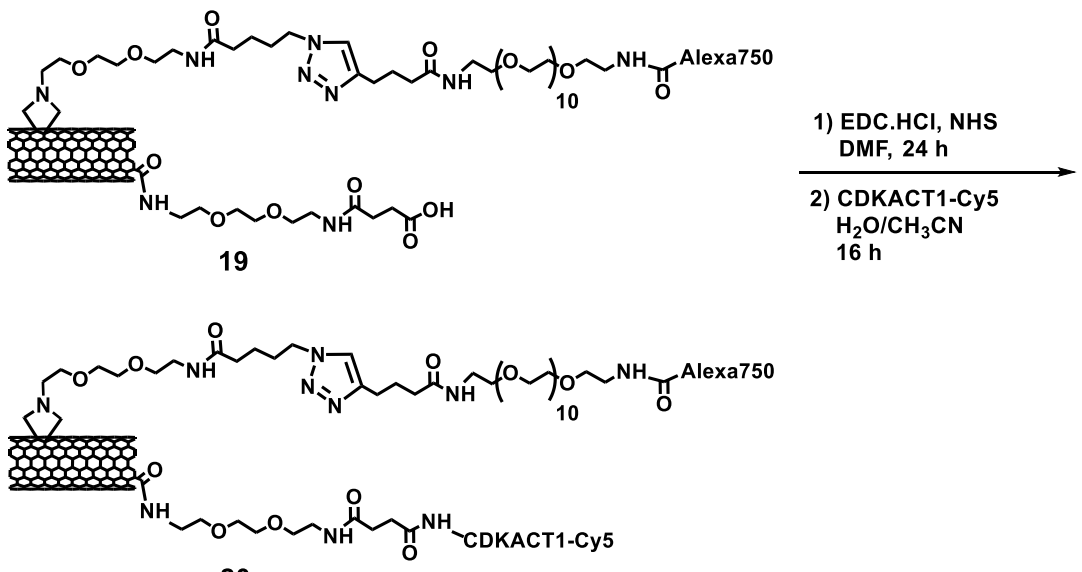

20

C

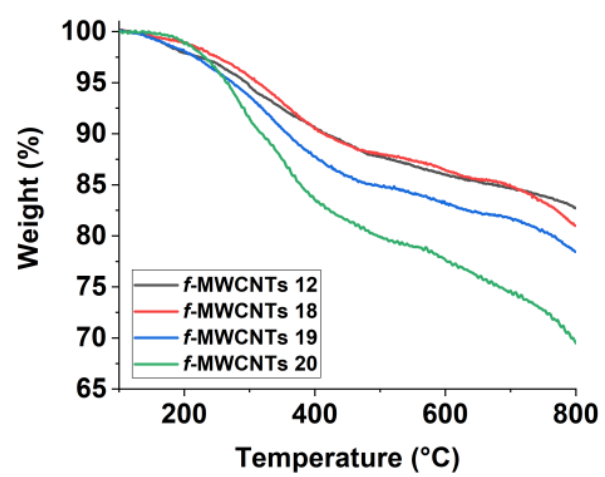

Figure S9. (A) Preparation of alkyne-PEG-Alexa 750 linker 16. (B) Synthesis of functionalized MWCNTs 20. C) TGA of functionalized MWCNTs 12, 18, 19, and 20 performed under $\mathrm{N}_{2}$. 
A

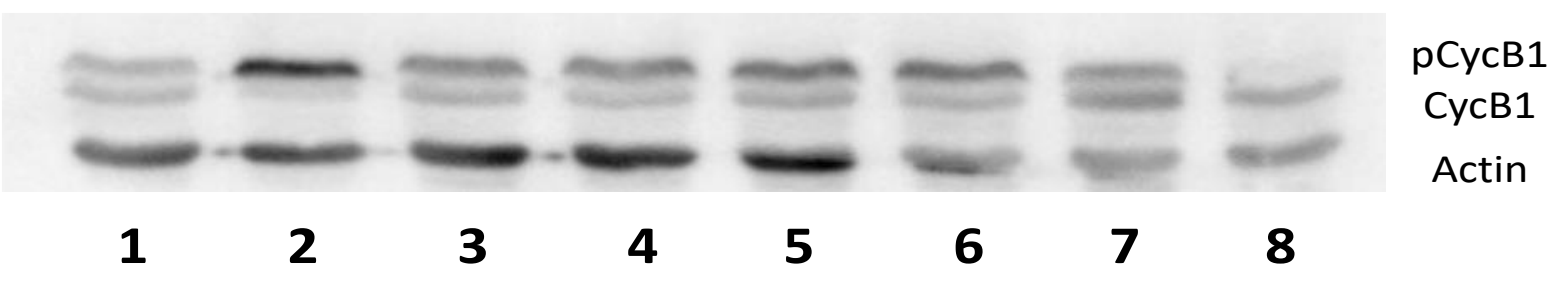

B

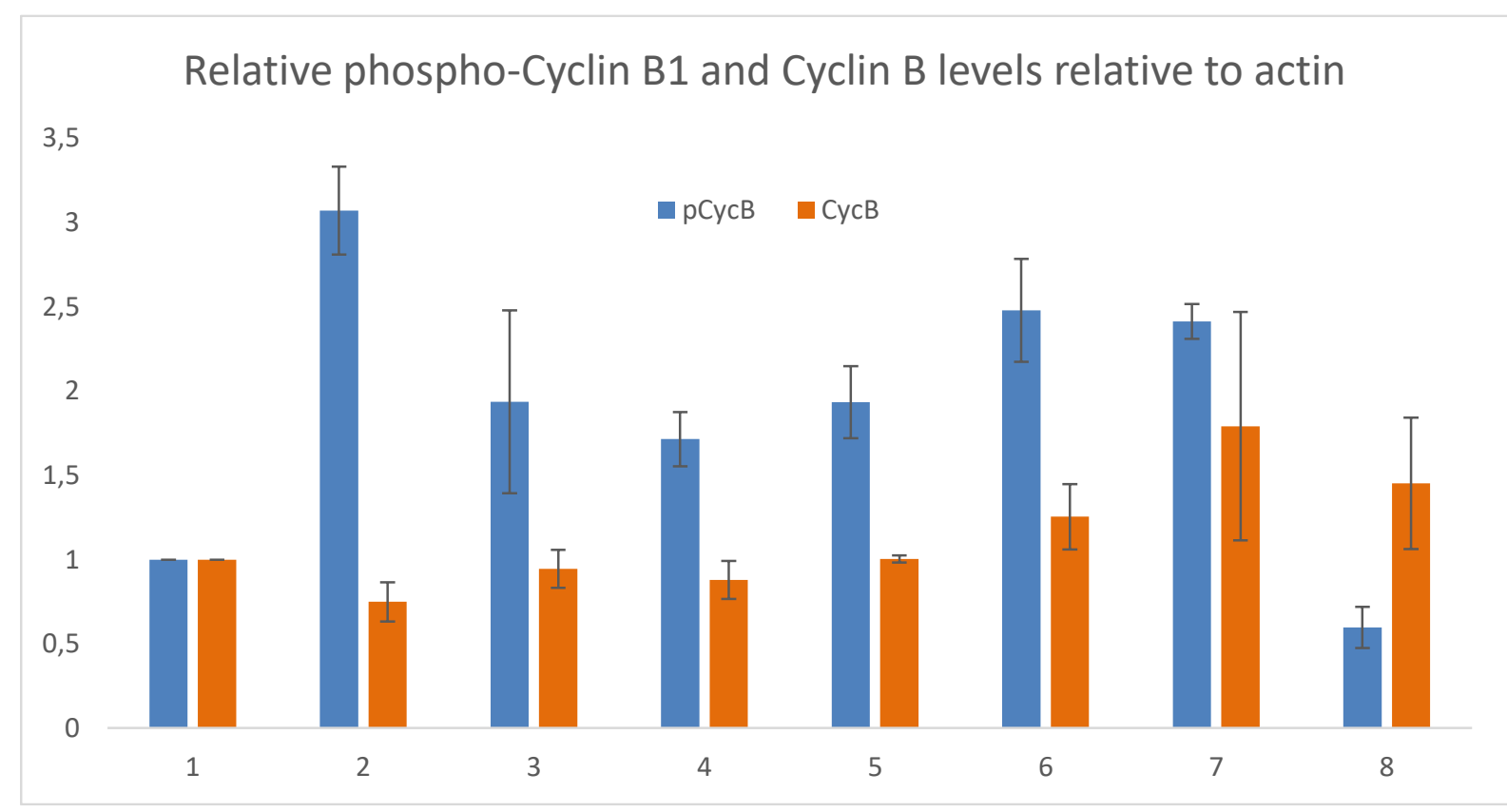

Lane 1: Mock-treated A375 cells

Lane 2: overnight treatment with $0.5 \mu \mathrm{g} / \mathrm{ml}$ Nocodazole

Lane 3: $15 \mathrm{~h}$ release after a $24 \mathrm{~h} 10 \mu \mathrm{M}$ Roscovitine treatment

Lane 4: 15 h release after a 24 h $10 \mu \mathrm{M}$ Roscovitine + $10 \mu \mathrm{M}$ RO-3306 double treatment

Lane 5: $1 \mathrm{~h}$ retreatment with $10 \mu \mathrm{M}$ Roscovitine following $15 \mathrm{~h}$ release after a $24 \mathrm{~h} 10 \mu \mathrm{M}$

Roscovitine treatment

Lane 6: $1 \mathrm{~h}$ retreatment with $10 \mu \mathrm{M}$ Roscovitine $+10 \mu \mathrm{M}$ RO-3306 following $15 \mathrm{~h}$ release after a 24 h $10 \mu \mathrm{M}$ Roscovitine + $10 \mu \mathrm{M}$ RO-3306 double treatment

Lane 7: $10 \mu \mathrm{M}$ Roscovitine for $24 \mathrm{~h}$

Lane 8: $10 \mu \mathrm{M}$ Roscovitine for $48 \mathrm{~h}$

Figure S10. (A) Western blotting of anti-cyclin B1 and anti-actin in mock-treated A375 cells (lane 1) following overnight treatment with $0.5 \mu \mathrm{g} / \mathrm{ml}$ Nocodazole (lane 2) or $10 \mu \mathrm{M}$ Roscovitine for $24 \mathrm{~h}$ (lane 7) or $48 \mathrm{~h}$ (lane 8), $15 \mathrm{~h}$ release after a $24 \mathrm{~h}$ Roscovitine treatment (lane 3) or $15 \mathrm{~h}$ release after a $24 \mathrm{~h} 10 \mu \mathrm{M}$ Roscovitine and $10 \mu \mathrm{M}$ RO-3306 double treatment 
(lane 4), followed by a $1 \mathrm{~h}$ retreatment with $10 \mu \mathrm{M}$ Roscovitine (lane 5) or a $1 \mathrm{~h}$ retreatment with $10 \mu \mathrm{M}$ Roscovitine and $10 \mu \mathrm{M}$ RO-3306 (lane 6). (B) Quantification of phospho-cyclin B1 (pCycB1) and cyclin B1 (CycB1) levels relative to actin levels, based on three independent experiments.

Compared to extracts from untreated cells (lane 1), phosphorylated cyclin B1 levels are significantly higher in cells treated overnight with Nocodazole, an inhibitor of microtubule polymerization which blocks cells in M-phase with active CDK1/Cyclin B1, which leads to autophosphorylation of cyclin B1 (lane 2). In contrast, phospho-cyclin B1 levels are significantly reduced in cells treated with $10 \mu \mathrm{M}$ Roscovitine for $48 \mathrm{~h}$, consistent with an Sphase block in which there is no active CDK1 (lane 8). A $24 \mathrm{~h}$ treatment with $10 \mu \mathrm{M}$ Roscovitine is insufficient to reduce phospho-cyclin B1 completely (lane 7). Moreover, phosphorylated cyclin B1 appears to accumulate $15 \mathrm{~h}$ after release following $10 \mu \mathrm{M}$ Roscovitine treatment for $24 \mathrm{~h}$ (lane 3) or $15 \mathrm{~h}$ after release following $10 \mu \mathrm{M}$ Roscovitine and $10 \mu \mathrm{M}$ RO3306 double treatment for $24 \mathrm{~h}$ (lane 4), and is slightly more pronounced after $14 \mathrm{~h}$ release following $10 \mu \mathrm{M}$ Roscovitine treatment for $24 \mathrm{~h}$, and an additional $1 \mathrm{~h}$ treatment with $10 \mu \mathrm{M}$ Roscovitine (lane 5) or after $15 \mathrm{~h}$ release following $10 \mu \mathrm{M}$ Roscovitine and $10 \mu \mathrm{M}$ R03306 double treatment for $24 \mathrm{~h}$, and an additional $1 \mathrm{~h}$ double treatment with $10 \mu \mathrm{M}$ Roscovitine and $10 \mu \mathrm{M}$ R03306 (lane 6).

These experiments reveal that treatment with Roscovitine for $48 \mathrm{~h}$ blocks cells in S-phase with unphosphorylated cyclin B1, indicative of inactive CDK1. In contrast $24 \mathrm{~h}$ treatment with Roscovitine is insufficient for a complete block, and only partially synchronizes cells in S-phase, with similar levels of unphosphorylated and phosphorylated cyclin B1. Washes and release from this treatment or a double treatment with Roscovitine and RO-3306 leads to further accumulation of phosphorylated cyclin B1. An additional $1 \mathrm{~h}$ treatment with Roscovitine or Roscovitine and RO-3306 has no significant inhibitory effect. In these experimental conditions, in which cells are concomitantly treated with Roscovitine and RO-3306, the later clearly has no inhibitory effect on cyclin B1 autophosphorylation. In fact, following release from the initial Roscovitine treatment, phospho-cyclin B1 levels increase.

\section{References}

[1] G. Pastorin, W. Wu, S. Wieckowski, J.-P. Briand, K. Kostarelos, M. Prato, A. Bianco, Chem. Commun. 2006, 21, 1182.

[2] C. Ménard-Moyon, C. Fabbro, M. Prato, A. Bianco, Chem. Eur. J. 2011, 17, 3222. 